Article

\title{
Improving the Oral Bioavailability of an Anti-Glioma Prodrug CAT3 Using Novel Solid Lipid Nanoparticles Containing Oleic Acid-CAT3 Conjugates
}

\author{
Hongliang Wang ${ }^{1,2}, \operatorname{Lin} \mathrm{Li}^{1,2}$, Jun $\mathrm{Ye}^{1,2}$, Rubing Wang ${ }^{1}$, Renyun Wang ${ }^{1,2}$, Jinping $\mathrm{Hu}^{1}$, \\ Yanan Wang ${ }^{1} \mathbb{1}$, Wujun Dong ${ }^{1,2}$, Xuejun Xia ${ }^{1,2}$, Yanfang Yang ${ }^{1,2}$, Yue Gao ${ }^{1,2}$, Lili Gao ${ }^{2}$ and \\ Yuling Liu ${ }^{1,2, *}$ \\ 1 State Key Laboratory of Bioactive Substance and Function of Natural Medicines, Institute of Materia Medica, \\ Chinese Academy of Medical Sciences \& Peking Union Medical College, Beijing 100050, China; \\ wanghl@imm.ac.cn (H.W.); llin@imm.ac.cn (L.L.); yelinghao@imm.ac.cn (J.Y.); \\ wangrubing@imm.ac.cn (R.W.); wry@imm.ac.cn (R.W.); hujp@imm.ac.cn (J.H.); \\ wangyanan@imm.ac.cn (Y.W.); dwujun@vip.sina.com (W.D.); xjxia@imm.ac.cn (X.X.); \\ yangyf@imm.ac.cn (Y.Y.); gaoyue@imm.ac.cn (Y.G.) \\ 2 Beijing Key Laboratory of Drug Delivery Technology and Novel Formulation, Institute of Materia Medica, \\ Chinese Academy of Medical Sciences \& Peking Union Medical College, Beijing 100050, China; \\ gaolili@imm.ac.cn \\ * Correspondence: ylliu@imm.ac.cn; Tel.: +86-10-8316-0332
}

Received: 12 January 2020; Accepted: 1 February 2020; Published: 3 February 2020

check for updates

\begin{abstract}
S)-3-pivaloyloxyl-6,7-dimethoxyphenanthro(9,10-b)-indolizidine (CAT3) is a novel oral anti-glioma pro-drug with a potent anti-tumor effect against temozolomide-resistant glioma in vivo. However, poor lipid solubility has limited the encapsulation efficacy during formulation development. Moreover, although the active metabolite of CAT3, 13a(S)-3-hydroxyl6,7-dimethoxyphenanthro(9,10-b)-indolizidine (PF403), can penetrate the blood-brain barrier and approach the brain tissue with a 1000-fold higher anti-glioma activity than CAT3 in vitro, its bioavailability and $C_{\max }$ were considerably low in plasma, limiting the anti-tumor efficacy. In this study, a novel oleic acid-CAT3 conjugate (OA-CAT3) was synthesized at the first time to increase the lipid solubility of CAT3. The OA-CAT3 loaded solid lipid nanoparticles (OA-CAT3-SLN) were constructed using an ultrasonic technique to enhance the bioavailability and $C_{\max }$ of PF403 in plasma. Our results demonstrated that CAT3 was amorphous in the lipid core of OA-CAT3-SLN and the in vitro release was well controlled. Furthermore, the encapsulation efficacy and the zeta potential increased to $80.65 \pm 6.79 \%$ and $-26.7 \pm 0.46 \mathrm{mV}$, respectively, compared to the normal CAT3 loaded SLN. As indicated by the high-performance liquid chromatography-mass spectrometry (HPLC-MS/MS) quantitation, the monolayer cellular transepithelial transport rate of OA-CAT3-SLN improved by 2.42-fold relied on cholesterol compared to the CAT3 suspension. Hence, the in vitro cell viability of OA-CAT3-SLN in C6 glioma cells decreased to $29.77 \% \pm 2.13 \%$ and $10.75 \% \pm 3.12 \%$ at 48 and $72 \mathrm{~h}$, respectively. Finally, compared to the CAT3 suspension, the in vivo pharmacokinetics in rats indicated that the plasma bioavailability and $C_{\max }$ of PF403 as afforded by OA-CAT3-SLN increased by 1.7- and 5.5-fold, respectively. Overall, the results indicate that OA-CAT3-SLN could be an efficacious delivery system in the treatment of glioma.
\end{abstract}

Keywords: phenanthroindolizidine; prodrug; oleic acid; conjugate; solid lipid nanoparticles; bioavailability 


\section{Introduction}

Glioblastoma multiforme (GBM) is an aggressive astrocytic cell neoplasm and is one of the leading causes of cancer-related deaths in both pediatric and adult populations, while also having poor clinical outcomes [1]. Notably, the median survival of patients with GBM is approximately 12-15 months after the initial diagnosis [2,3]. In 1999, the US Food and Drug Administration indicated oral temozolomide (TMZ), a DNA alkylating agent, as a first-line agent in the treatment of refractory anaplastic astrocytoma; in 2005, this indication was expanded to newly diagnosed glioblastoma patients [4,5]. However, temozolomide has been associated with severe toxicity, with the ensuing drug resistance limiting the efficacy and clinical use [6,7]. Therefore, it is necessary to further expand the development of novel therapeutic agents.

CAT3 (Figure 1A) is a novel phenanthroindolizidine substance that selectively inhibits the hedgehog signaling pathway, demonstrating a significant inhibitory effect in GBM and TMZ-resistant GBM in orthotopic glioblastoma mice models following oral administration [8-10]. Moreover, central nervous system toxicity, one of the main obstacles in the development of phenanthroindolizidines, has not been associated with CAT3 [11]. PF403 (Figure 1B), reporting an in vitro anti-glioma activity approximately 1000 times higher than CAT3 [8] in human cell lines, is the active metabolite of CAT3 synthesized by esterases in vivo and can penetrate the blood-brain barrier to demonstrate an anti-glioma effect [12-14]. Although CAT3 can be absorbed via the gastrointestinal tract, it is a biopharmaceutics classification system class IV drug, insoluble in water, with poor bio-membrane permeability, and demonstrating low bioavailability and $C_{\max }$ of its active metabolite, PF403, in vivo. Moreover, the lipid solubility of CAT3 is also poor, further increasing the challenges associated with the development of appropriate lipid delivery vehicles. Hence, the poor bioavailability and the low aqueous and lipid solubilities remained crucial obstacles to the clinical application of CAT3.
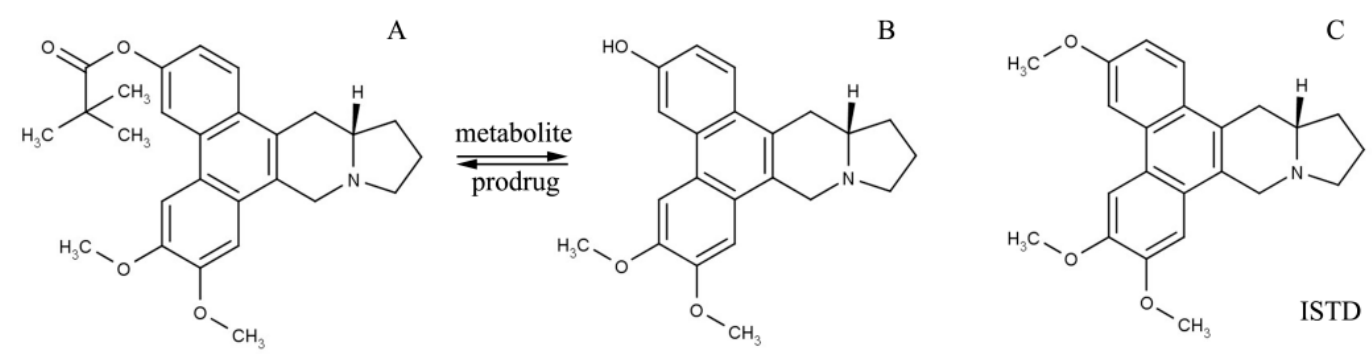

Figure 1. Molecular structure of CAT3 (A) as the pro-drug, PF403 (B) as the active in vivo metabolite, and (+)-Deoxytylophorinine (CAT) (C) as the internal standard (ISTD) of the drug concentration test in plasma.

Solid lipid nanoparticles (SLN) are interesting vectors for the oral delivery of lipophilic substances due to the excellent biocompatibility and assistance in drug uptake $[15,16]$. These nanoparticles can be prepared without the use of organic solvents and can be easily scaled up from laboratory to large-scale manufacture [17]. Moreover, as a lipid-based drug delivery system, SLN has been known to control drug release [18], promote oral absorption of drugs, modify the pharmacokinetics and pharmacodynamics [19,20], enhance tissue or cell-specific targeting [21], adjust tissue distribution [20], and reduce side effects [22-24]. Hence, SLN could be a superior drug delivery system to load CAT3 and improve bioavailability.

However, it has been reported that the lipid core of SLN demonstrates a perfect crystal lattice and cannot contain an excess amount of drug molecules [25]. During the encapsulation of CAT3 in SLN, the same phenomenon was observed, and the drug loading (DL) and the encapsulation efficiency (EE) were extremely low. Previously, studies have reported that some type of liquid lipid, for example, low melting point fatty acids or oils, could be used to formulate a less-ordered crystalline structure of the lipid core, increasing the DL and EE [26]. To construct the CAT3 loaded SLN, several liquid 
lipids were tested and oleic acid (OA) was selected as an ideal agent. OA is a commonly used lipid to prepare SLN $[27,28]$, with its carboxyl group forming an ionic bond with the CAT3 nitrogen atom, resulting in a conjugate that improves lipid solubility. Moreover, even with identical compositions and contents in the SLN, the results obtained by the different methods of preparation differed significantly. The product obtained by conjugating OA and CAT3 (OA-CAT3) first, and preparing the SLN next demonstrated a higher solubility in lipids, with a higher DL and EE than the normal SLN, prepared by simply mixing together CAT3 and OA. Hence, OA-CAT3 may be a key complex contributing to the preparation of the SLN.

This study aimed to formulate a novel OA-CAT3 by linking OA and CAT3 through ionic bonding to overcome the challenges of CAT3 insolubility in lipids, forming the OA-CAT3 loaded SLN (OA-CAT3-SLN) using a hot ultra-sonication technique. Simultaneously, normal CAT3 loaded SLN (CAT3-SLN, with the same composition and contents as OA-CAT3-SLN except for the advanced preparation of OA-CAT3) were prepared using the same technique to explore the OA-CAT3 mechanism promoting the encapsulation of CAT3 by SLN. Furthermore, we evaluated the extent of bioavailability improvement in the active metabolite, PF403, by OA-CAT3-SLN. To achieve these goals, the size distribution, zeta potential, DL, EE, solid-state characterization of the drug, and in vitro release were compared between OA-CAT3-SLN and CAT3-SLN. Furthermore, the Caco-2 cellular uptake, Madin-Darby canine kidney cells transfected with the human MDR1 gene (MDCK-MDR1) monolayer transfer, and the C6 glioma cell cytotoxic activity of OA-CAT3-SLN were evaluated in vitro. Finally, an in vivo pharmacokinetic evaluation of OA-CAT3-SLN was conducted in Sprague-Dawley (SD) rats using the CAT3 suspension, OA-CAT3, and CAT3-SLN as controls.

\section{Materials and Methods}

\subsection{Materials}

CAT3 (purity $>99 \%$ ), PF403 (purity $>99 \%$ ), and (+)-Deoxytylophorinine (CAT) (purity $>99 \%$ ) were prepared at our institute (Institute of Materia Medica, Chinese Academy of Medical Sciences \& Peking Union Medical College, Beijing, China), and the structures were confirmed by infrared, two-dimensional nuclear magnetic resonance, and Fourier transform mass spectrometry. OA and Lipoid S75 (soy lecithin with $68 \%$ phosphatidylcholine) were both purchased from Lipoid KG (Ludwigshafen, Germany). Poloxamer188 (Pluronic F68) and Tween 80 were received as gifts from BASF (Ludwigshafen, Germany). Compritol 888 ATO was received as a gift from Gattefosse (Saint-Priest Cedex, France). The solvents for high-performance liquid chromatography (HPLC) were obtained from Thermo Fisher Scientific (Waltham, MA, USA). All other chemicals used were of analytical grade.

\subsubsection{Cell Culture}

MDCK-MDR1 cells expressing a high level of P-gp were generously provided by Professor Li (Institute of Materia Medica, Chinese Academy of Medical Sciences \& Peking Union Medical College, Beijing, China). Luciferase-expressing C6 glioma cells (C6-luc) were generously provided by Professor Huang (Institute of Materia Medica, Chinese Academy of Medical Sciences \& Peking Union Medical College, Beijing, China). Caco-2 cells were purchased from the Cell Resource Center, Peking Union Medical College (Beijing, China). MDCK-MDR1, C6, and Caco-2 cells were cultured in Dulbecco's Modified Eagle's Medium (Hyclone, Logan, UT, USA) supplemented with $10 \%$ fetal bovine serum (Gibco, Thermo Fisher Scientific) and 1\% penicillin/streptomycin (Gibco, Thermo Fisher Scientific) under $5 \% \mathrm{CO}_{2}$ at $37^{\circ} \mathrm{C}$.

\subsubsection{Animals}

Sprague Dawley rats (males, 200-250 g) were purchased from Beijing Vital River Laboratory Animal Technology (Beijing, China), and were raised at the Institute of Material Medica, the Chinese Academy of Medical Sciences, and the Peking Union Medical College (Beijing, China). The experiments 
were performed under the approval of the Laboratory Animal Care and Use Committee of the Peking Union Medical College on 11 April 2017 and the animal experiment lasted to 25 November 2017 (project identification code 00005964). All animal experiments were performed in accordance with the guidelines of laboratory animals-guidelines for ethical review of animal welfare (GB_T 35892.2018).

\subsection{Methods}

\subsubsection{Preparation and Spectral Analysis of OA-CAT3}

OA-CAT3 was prepared by the addition of CAT3 into the excess OA (the molar ratio was 1:7) and by maintaining the mixture in the ultrasonic cleaning machine at $45^{\circ} \mathrm{C}$ for $30 \mathrm{~min}$. After an additional $10 \mathrm{~h}$ at $45^{\circ} \mathrm{C}$, the OA-CAT3 was obtained as a clear yellowish oil, which was used to prepare the OA-CAT3-SLN. The reaction time and temperature were optimized using nuclear magnetic resonance (NMR), differential scanning calorimetry (DSC), and Fourier transform infrared spectroscopy (FTIR). In addition, $45^{\circ} \mathrm{C}$ was selected to avoid the darkening of $\mathrm{OA}$ due to the oxidation by the air at higher temperatures.

To reduce the interference of excess OA in the results, the OA-CAT3 sample was prepared at a molar ratio of 1:1 and analyzed by ${ }^{1} \mathrm{H}$ NMR, FTIR, and DSC. Briefly, equimolar CAT3 and OA was added to a solution of acetonitrile and the mixture was heated under reflux for $2 \mathrm{~h}$. After concentration under reduced pressure, the residue was washed with diethyl ether and then concentrated to afford OA-CAT3.

${ }^{1} \mathrm{H}$ NMR (600 MHz) spectra were recorded in dimethyl sulfoxide (DMSO) on a Bruker-Avance 600 spectrometer at $303 \mathrm{~K}$ and with tetramethylsilane (TMS) as an internal standard (chemical shifts ( $\delta$ ) in parts per million, coupling constants $(\mathrm{J})$ in hertz).

CAT3 FTIR spectra were obtained using an FTIR spectrometer (Nicolet 5700 FTIR Spectrometer, Thermo Fisher Scientific, Waltham, MA, USA). CAT3 (equivalent to $2 \mathrm{mg}$ ) was mixed with $\mathrm{KBr}$ (about $30 \mathrm{mg}$ ) and ground into a fine powder using an agate mortar, before compressing into the $\mathrm{KBr}$ disk under a press at 10,000 psi. The baseline was corrected, and the samples were scanned against a blank $\mathrm{KBr}$ pellet background at a wave number ranging between 4000 and $400 \mathrm{~cm}^{-1}$ with a resolution of $4.0 \mathrm{~cm}^{-1}$, with 64 scans. Next, the characteristic peaks were recorded. To test the OA-CAT3 and the $\mathrm{OA}$, the same instrument equipped with an infrared microscope (Nicolet Centaur $\mu$ s, Thermo Fisher Scientific) was used.

DSC 6200 (Seiko Instruments, Tokyo, Japan) was used to obtain the thermograms of CAT3, OA, and OA-CAT3. The indium $\left(156.6 \pm 0.2{ }^{\circ} \mathrm{C}\right)$ and zinc $\left(419.5 \pm 0.3{ }^{\circ} \mathrm{C}\right)$ standards were used to calibrate the melting point of the apparatus. The heat flow and enthalpy of the apparatus were calibrated by the indium heat of fusion $\left(28.58 \pm 0.3 \mathrm{~J} \cdot \mathrm{g}^{-1}\right)$. The samples were placed in the standard aluminum sample pans and an empty pan was used as a reference. The samples were tested at between the temperature range of -20 and $250{ }^{\circ} \mathrm{C}$ at the heating rate of $10^{\circ} \mathrm{C} / \mathrm{min}$ for OA and OA-CAT3, and the range of 28 and $280^{\circ} \mathrm{C}$ for CAT3, as it is a solid drug at $25^{\circ} \mathrm{C}$ and there was no need to start the test from an extremely low temperature. Nitrogen was used as the gas purged at a flow rate of $60 \mathrm{~mL} / \mathrm{min}$.

\subsubsection{Preparation of OA-CAT3-SLN and CAT3-SLN}

The main preparation processes of OA-CAT3-SLN and CAT3-SLN are shown in Figure 2. Both formulations were prepared using hot homogenization followed by the hot ultra-sonication method [29,30]. To prepare the OA-CAT3-SLN, compritol 888 ATO $0.3 \mathrm{~g}$ and Lipoid S75 $0.2 \mathrm{~g}$ were heated to $80^{\circ} \mathrm{C}$ and dissolved as the oil phase. Next, approximately $60 \mathrm{mg}$ of OA-CAT3 (containing $10 \mathrm{mg}$ of CAT3) was dispersed in the oil phase. Additionally, $9.3 \mathrm{~mL}$ aqueous solution of surfactant (containing $0.1 \mathrm{~g}$ each of Tween 80 and Poloxamer188) was heated to the same temperature and referred to as aqueous phase. The aqueous phase and oil phase were then mixed sufficiently using the homogenizer (FA25, Fluko Equipment, Shanghai, China) at 16,000 rpm for about $3 \mathrm{~min}$ in a water bath at $80^{\circ} \mathrm{C}$. The obtained dispersion was sonicated with the help of a "Probe Sonicator" (Sonic prepultra homogenizer, Osterode, Germany) for $8 \mathrm{~min}$ at $300 \mathrm{Watt}$ in an $80^{\circ} \mathrm{C}$ water bath. Then, the 
OA-CAT3-SLN suspension was obtained after cooling in an ice bath, sealed in a glass vial, and stored at $4{ }^{\circ} \mathrm{C}$. Similarly, the CAT3-SLN was prepared by the same method except for the solution of $10 \mathrm{mg}$ CAT3 that was dissolved in $50 \mathrm{mg} \mathrm{OA}$ directly and then added into the oil phase without prior formation of OA-CAT3. The blank SLN was prepared using the same method with the absence of CAT3. The amount of all ingredients and the preparation parameters were optimized with the minimum particle size, and the maximum DL and EE to ensure the quality of SLN products.

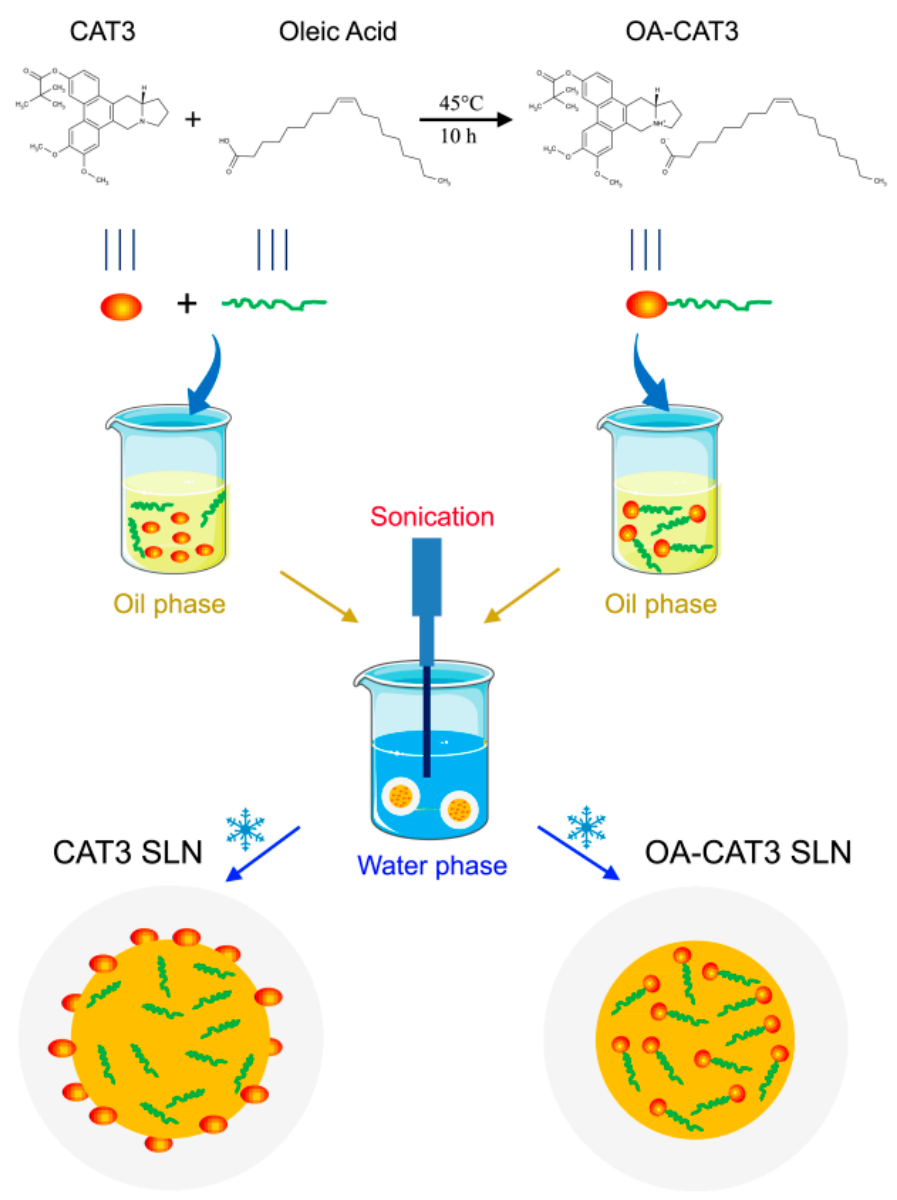

Figure 2. Main preparation process of OA-CAT3-SLN and CAT3-SLN.

\subsubsection{Physicochemical Characterization of OA-CAT3-SLN and CAT3-SLN}

\section{Morphology and Particle Size}

The morphological evaluation of OA-CAT3-SLN was carried out by transmission electron microscopy (TEM, JEM-1400 plus; JEOL, Tokyo, Japan). The OA-CAT3-SLN was diluted with deionized (DI) water at a ratio of 1:100 and mixed by slight shaking. One drop of the diluted sample was deposited on a film-coated copper grid and negatively stained with $2 \%(\mathrm{w} / \mathrm{v})$ phosphotungstic acid before observation under the electron microscope.

The average particle size, polydispersity index (PDI), and zeta potential of the prepared SLN were measured by photon correlation spectroscopy using a Malvern Zetasizer Nano ZS90 (Malvern Instruments, Malvern, UK). The samples were diluted with DI water (1:100) and the measurements were performed at $25^{\circ} \mathrm{C}$. The scattering angle for measurement was $90^{\circ}$. To measure of particle size and PDI, the samples were placed in disposable polystyrene cells. For the zeta potential measurements, the samples were placed in disposable plain folded capillary zeta cells. All experiments were performed in triplicates and the data were analyzed using built-in software. The results are represented as the mean \pm standard deviation. 
Differential Scanning Calorimetry (DSC) and Powder X-ray Diffractometry (PXRD)

Differential scanning calorimetry (DSC) and powder X-ray diffractometry (PXRD) were used to identify the crystal stage of CAT3 present in the OA-CAT3-SLN or CAT3-SLN. As both DSC and PXRD required a solid sample for measurement, SLN samples (including OA-CAT3-SLN, CAT3-SLN, and the blank SLN) were subjected to lyophilization for $48 \mathrm{~h}$ using a freeze-drying apparatus (Alpha 1-4, Martin Christ, Osterode, Germany) under standard conditions.

The DSC analyses of OA-CAT3-SLN, CAT3-SLN, blank SLN, CAT3, and the physical mixture of blank SLN and the CAT3 were performed in the temperature range of $28-280{ }^{\circ} \mathrm{C}$, with a heating rate of $10{ }^{\circ} \mathrm{C} / \mathrm{min}$.

The X-ray diffraction patterns of lyophilized OA-CAT3-SLN, CAT3-SLN, blank SLN, CAT3, and the physical mixture of blank SLN and the CAT3 were studied using a powder X-ray diffractometer (D8 Advance-Bruker, Billerica, MA, USA). PXRD studies were performed by exposing the samples to $\mathrm{Cu} \mathrm{K} \alpha$ radiation $(40 \mathrm{kV}, 30 \mathrm{~mA})$ and scanned from $2-60^{\circ}, 2 \theta$ at a step size of $0.045^{\circ}$ and step time of $0.5 \mathrm{~s}[30,31]$.

Drug Loading (DL) and Encapsulation Efficiency (EE)

The DL and EE of CAT3 incorporated in OA-CAT3-SLN or CAT3-SLN were determined by spectrophotometric analysis using a UV-visible spectrophotometer HP 8453 (Agilent Technologies, Santa Clara, CA, USA) at $263 \mathrm{~nm}$. Prior to the total CAT3 content analysis, OA-CAT3-SLN and CAT3-SLN were dissolved in ethanol at $50{ }^{\circ} \mathrm{C}$ and filtered using a $0.22 \mu \mathrm{m}$ polyvinylidene fluoride (PVDF) syringe filter.

The efficiency of CAT3 entrapped in SLN was calculated using the ultracentrifugation method using centrifugal devices (Amicon ${ }^{\circledR}$ Ultra-4 100k, Millipore, Billerica, MA, USA) with a cut-off membrane of $100 \mathrm{kDa}$ [32]. Briefly, SLN (1 mL) were placed in the ultrafiltration tubes and centrifuged in a high-speed Dragon D3024R Lab cooling centrifuge (Dragon Laboratory Instruments, Beijing, China) at $15,000 \mathrm{~g}$ for $30 \mathrm{~min}$ at $4{ }^{\circ} \mathrm{C}$. The amount of free CAT3 in the ultra-filtrate solution was analyzed by spectrophotometric analysis.

The DL and EE (\%) of SLN were estimated by using the following equations.

$$
\begin{gathered}
\text { Drug Loading }(\%)=\frac{\text { amount of total CAT3 }- \text { free CAT3 }}{\text { amount of carriers }+ \text { total CAT3 }- \text { free CAT3 }} \\
\text { Encapsulation Efficiency }(\%)=\frac{\text { amount of total CAT3 }- \text { free CAT3 }}{\text { amount of total CAT3 }} \times 100
\end{gathered}
$$

In Vitro Release and Releasing Mechanism

Drug release from SLN was monitored in vitro under simulated gastrointestinal conditions. The tests were performed by placing $2 \mathrm{~mL}$ SLN samples (containing $2 \mathrm{mg}$ CAT3) into $400 \mathrm{~mL}$ of the dissolution medium maintained at $37^{\circ} \mathrm{C}$. The dissolution media contained $0.1 \%$ SDS $(\mathrm{w} / \mathrm{v})$ to meet sink conditions. Preswollen 8-10 kDa MWCO dialysis bags (Sigma-Aldrich, Madrid, Spain), which contained $5 \mathrm{~mL}$ of the blank SDS solution with the same concentration, were placed into the dissolution flask $(n=3)$. The release behavior of CAT3 was compared under the same condition by placing $5 \mathrm{mg}$ CAT3 powder into the $1000 \mathrm{~mL}$ media. The samples $(1 \mathrm{~mL})$ were withdrawn at predetermined time points from the dialysis bags and replaced with the same amount of fresh medium maintained at $37^{\circ} \mathrm{C}$. The samples were centrifuged for $5 \mathrm{~min}$ at 12,000 rpm, and the resultant supernatants were quantified for drug content. The samples were protected from light during the experiments. The DDsolver software $[33,34]$ was used to evaluate the drug-release kinetics. An Excel worksheet (Microsoft Corporation, Redmond, WA, USA) was used to control the computing method for comparison with the results obtained using the DDSolver program. According to the example format for each built-in 
module of the DDSolver, all data were entered into Excel. The relevant parameters were calculated following the step-by-step equations utilizing an Excel spreadsheet.

\subsubsection{In Vitro and In Vivo Bio Evaluation of OA-CAT3-SLN}

\section{Transepithelial Transport Study}

The permeabilities of CAT3 and OA-CAT3-SLN were investigated on an MDCK-MDR1 cell monolayer. MDCK-MDR1 cells were seeded onto 12-well transwell ${ }^{\circledR}$ filter inserts (pore size $0.4 \mu \mathrm{m}$, surface area $1.12 \mathrm{~cm}^{2}$; Corning Incorporated, Corning, NY, USA) at a density of $2 \times 10^{5}$ cells/well. The culture medium was changed every $24 \mathrm{~h}$ for seven days, and the cell monolayers with a transepithelial electrical resistance (TEER) above $110 \Omega \cdot \mathrm{cm}^{2}$ were used for the transport experiments. Prior to performing the TEER test, the culture medium was removed, and the monolayer was pre-incubated with $0.5 \mathrm{~mL}$ of Hanks' balanced salt solution (HBSS) for $20 \mathrm{~min}$ at $37^{\circ} \mathrm{C}$.

After measuring TEER, HBSS was removed, and $0.5 \mathrm{~mL}$ of $100 \mathrm{ng} / \mathrm{mL}$ CAT3 or the same concentration of OA-CAT3-SLN diluted with HBSS was added to the apical side (AP), and $1.5 \mathrm{~mL}$ of HBSS was added to the basolateral (BL) compartment. The monolayer was incubated for $2 \mathrm{~h}$ at $37^{\circ} \mathrm{C}$. Samples $(50 \mu \mathrm{L})$ were obtained from the BL compartment at $0.5,1,1.5$, and $2 \mathrm{~h}$. Next, the samples were stored at $4{ }^{\circ} \mathrm{C}$ for analysis.

To investigate the mechanism of cellular internalization of OA-CAT3-SLN, various specific endocytic inhibitors were evaluated in the uptake study. Chlorpromazine $(10 \mu \mathrm{g} / \mathrm{mL})$ was used as the clathrin-mediated endocytic inhibitor, nystatin $(5 \mu \mathrm{g} / \mathrm{mL})$ as the caveolae structure and function abolisher, and methyl- $\beta$-Cyclodextrin (MCYP, $13 \mathrm{mg} / \mathrm{mL}$ ) as the disruptor of lipid rafts [35-37]. The inhibitors were added to the cell monolayer and pre-treated for $30 \mathrm{~min}$ before the test. After the treatments, the cells were treated with OA-CAT3-SLN for a further $2 \mathrm{~h}$ using the same method. To investigate whether the GTPase dynamin played an important role in endocytosis, the permeability of OA-CAT3-SLN was investigated at $4{ }^{\circ} \mathrm{C}$.

The amount of CAT3 or OA-CAT3-SLN that permeated that through the monolayer was determined using the liquid chromatography-mass spectrometry (LC-MS/MS) system. The apparent permeability coefficient $\left(P_{\text {app }}\right)$ of CAT3 or OA-CAT3-SLN was calculated according to the following equation: $P_{\text {app }}$ $=\mathrm{d} Q / \mathrm{d} t \times 1 /\left(A \times C_{0}\right)$, where $\mathrm{d} Q / \mathrm{d} t$ indicates the linear appearance rate of mass at the BL side $(\mu \mathrm{mol} / \mathrm{s})$, $C_{0}$ is the initial concentration of CAT3 or OA-CAT3-SLN on the AP side $(\mu \mathrm{mol} / \mathrm{mL})$, and $A$ is the surface area of the monolayer $\left(\mathrm{cm}^{2}\right)$.

\section{In vitro Cellular Uptake Study}

To verify whether SLN can enhance intracellular delivery, a fluorescence microscopic study was performed on the Caco- 2 cells and C6 cells. Fluorescent coumarin 6 (Cou-6) was loaded in the blank SLN [38]. Caco-2 and C6 cells were seeded in six-well plates containing a cover glass seeded with $2 \times 10^{5}$ cells/well in the cell culture medium overnight. Cou-6 loaded SLN or the Cou- 6 solution in 2 mL DMEM medium (Cou- 6 concentration: $100 \mathrm{ng} / \mathrm{mL}$ ) was added and incubated at $37^{\circ} \mathrm{C}$ for $1 \mathrm{~h}$. Simultaneously, another Cou-6 loaded SLN was incubated at $4{ }^{\circ} \mathrm{C}$ for $1 \mathrm{~h}$. To validate the cellular uptake through lipid rafts, $13 \mathrm{mg} / \mathrm{mL}$ MCYP was added into another well containing Caco-2 cells and was pre-treated for $30 \mathrm{~min}$ before conducting the test at $37^{\circ} \mathrm{C}$. After incubation with the Cou-6, the cells were washed three times with cold phosphate-buffered saline (PBS) and fixed with $4 \%$ paraformaldehyde for $15 \mathrm{~min}$. Next, the cells were washed three times with cold PBS and stained with 4',6-diamidino-2-phenylindole (DAPI). Later, the coverslips were visualized using a laser scanning confocal microscope (LSCM, Leica TCS SP8 X, Wetzlar, Germany) using appropriate excitation and emission wavelengths (405/450 $\mathrm{nm}$ for DAPI and 470/504 $\mathrm{nm}$ for Cou-6) [38,39]. 
In Vitro Cytotoxicity Analysis

Cytotoxicity of the CAT3 suspension, OA-CAT3-SLN, and blank SLN against the C6 brain glioma cell line was measured by 3-(4,5-dimethylthiazol-2-yl)-2,5 diphenyltetrazolium bromide (MTT) assay. Briefly, the cells were seeded into 96-well plates at a cell density of $2 \times 10^{4}$ cells/mL (100 $\left.\mu \mathrm{L} / \mathrm{well}\right)$. After $24 \mathrm{~h}$ of incubation, the cells were further incubated for 24, 48, and $72 \mathrm{~h}$ in fresh DMEM complete medium containing $0.64 \mathrm{ng} / \mathrm{mL}$ CAT3 suspension, OA-CAT3-SLN, or the blank SLN, respectively. At the above-mentioned time points, the culture medium was replaced by the MTT solution $(0.5 \mathrm{mg} / \mathrm{mL}$, $200 \mu \mathrm{L} /$ well), followed by incubation for further $4 \mathrm{~h}$. The supernatant was removed and $100 \mu \mathrm{L}$ of DMSO solution was added to the wells. The absorbance values of each well were measured at 570 nm using a microplate reader (Synergy H1 Hybrid Multi-Mode Microplate Reader, BioTek, Winooski, VT, USA).

In Vivo Bioavailability Studies

For in vivo analysis of CAT3 and its metabolite, PF403, in the rat plasma, $10 \mu \mathrm{L}$ of the internal standard (ISTD) and ((+)-Deoxytylophorinine, CAT, $10 \mathrm{ng} / \mathrm{mL})$ was added to $50 \mu \mathrm{L}$ of plasma. After the addition of $90 \mu \mathrm{L}$ of acetonitrile for the precipitation of protein, the sample was vortex-mixed for $30 \mathrm{~s}$, followed by centrifugation at 13,000 rpm for $10 \mathrm{~min}$. The supernatant was transferred to a new tube, and a 5- $\mu \mathrm{L}$ aliquot of the solution was injected into the LC-MS/MS for analysis.

Triple-quadrupole mass spectroscopy (6410B, Agilent, Santa Clara, CA, USA) was performed under multiple reaction monitoring and a positive electrospray ionization mode. Nitrogen $\left(350{ }^{\circ} \mathrm{C}\right)$ as the nebulizer gas was flown at $10 \mathrm{~L} / \mathrm{min}$ and the pressure was set to $40 \mathrm{psi}$. The voltages of the fragmentor potential and collision energy were 135 and $20 \mathrm{eV}$, respectively. The ion reactions for the determination of CAT3, PF403, and ISTD were $m / z 434.3 \rightarrow m / z 70.1,350.2 \rightarrow 70.1$, and 364.2 $\rightarrow 70.1$, respectively.

The analyte concentrations were determined using the MassHunter software (Agilent). Chromatographic separation was performed on a 1200 serious RRLC system (Agilent) with a $C_{18}$ column ( $50 \mathrm{~mm}$ by $2.1 \mathrm{~mm}, 1.8 \mu \mathrm{m}$, Agilent) and a corresponding guard column (ODS, $5 \mu \mathrm{m})$. DI water and $0.1 \%$ formic acid acetonitrile $(20: 80, v / v)$ were used as the mobile phase for elution. The flow rate was $0.4 \mathrm{~mL} / \mathrm{min}$ at $40^{\circ} \mathrm{C}$.

The primary pharmacokinetic parameters were calculated based on the statistical moment method using Drug and Statistics (DAS) 3.0 software (BioGuider Medicinal Technology Co. Ltd., Shanghai, China). Parameters included: Peak concentration $\left(C_{\max }\right)$, time of peak concentration $\left(T_{\max }\right)$, area under the concentration-time curve from $0 \mathrm{~h}$ to $t\left(\mathrm{AUC}_{0-t}\right)$, area under the concentration-time curve from $0 \mathrm{~h}$ to $\infty\left(\mathrm{AUC}_{0-\infty}\right)$, average residence time from $0 \mathrm{~h}$ to $t\left(\mathrm{MRT}_{0-t}\right)$, average residence time from $0 \mathrm{~h}$ to $\infty$ $\left(\mathrm{MRT}_{0-\infty}\right)$, and elimination half-life of the drug concentration $\left(t_{1 / 2 \mathrm{z}}\right)$. The non-compartmental model was used to estimate the pharmacokinetic parameters.

For pharmacokinetic studies, 24 rats were divided into four groups ( $n=6$ per group). Prior to the day of administration, the rats were fasted for $12 \mathrm{~h}$, allowing water ad libitum. OA-CAT3-SLN (10 $\mathrm{mg} / \mathrm{kg}$ ) or the same dose of the CAT3 suspension (dispersed in 0.5\% CMC-Na solution), OA-CAT3, and CAT3-SLN was administered orally and the drug content was pre-analyzed by spectrophotometric methods at $263 \mathrm{~nm}$ to ensure dose accuracy. Blood samples (about $150 \mu \mathrm{L}$ ) were collected into heparinized tubes from each rat through a retro-orbital sinus puncture that was performed at 0,5 , 10,15 , and $30 \mathrm{~min}$ and $1,2,4,6,8,12$, and $24 \mathrm{~h}$ after oral administration. The blood samples were immediately processed to obtain the plasma by centrifuging at $4000 \mathrm{rpm}$ for $10 \mathrm{~min}$. Plasma was collected and frozen at $-80^{\circ} \mathrm{C}$ until analysis by LC-MS/MS.

\subsubsection{Statistical Analysis}

The statistical difference between the treatments was evaluated using the Analysis of Variance (ANOVA) test. Data are reported as mean \pm standard deviation (SD). Statistical significance of 
differences was evaluated by Duncan's multiple range test $(p \leq 0.05)$ using SPSS software version 17.0 (SPSS Inc., Chicago, IL, USA).

\section{Results}

3.1. Characterization of OA-CAT3 by NMR, Fourier Transform Infrared Spectroscopy (FTIR), and Differential Scanning Calorimetry (DSC)

Figure 2 shows the reaction method between the CAT3 and OA. Figure $3 \mathrm{~A}$ shows the ${ }^{1} \mathrm{H}$ NMR spectra comparison of CAT3 and OA-CAT3. The chemical shifts at 3.4, 3.6, and 4.6 ppm were assigned to the five protons beside the nitrogen atom of CAT3. When the nitrogen atom combined with the hydrogen ion of carboxyl in OA, their chemical shifts moved to the lower field, indicating the formation of a conjugate linkage.

The successful conjugation of OA-CAT3 was also proved by FTIR analysis. The FTIR spectra of CAT3, OA, and OA-CAT3 are presented in Figure 3B. The band at $2793 \mathrm{~cm}^{-1}$ of OA-CAT3 can be referred to $\mathrm{NH}^{+}$asymmetric stretching $\left(v_{\mathrm{as}} \mathrm{NH}^{+}\right)$. Furthermore, the bands at $1560 \mathrm{~cm}^{-1}$ and $1330 \mathrm{~cm}^{-1}$ of OA-CAT3 can be referred to $\mathrm{COO}^{-}$asymmetric stretching $\left(v_{\text {as }} \mathrm{COO}^{-}\right)$. Next, the absorption band at $1172 \mathrm{~cm}^{-1}$ of OA-CAT3 was attributed to $v_{\text {as }} \mathrm{C}-\mathrm{N}$. Finally, the prominent bands at $1413 \mathrm{~cm}^{-1}$ and $938 \mathrm{~cm}^{-1}$ were assigned to the $-\mathrm{OH}$ in-of-plane and out-of-plane bending of the carboxyl group of $\mathrm{OA}$, respectively. These bands disappeared from the spectra for OA-CAT3, indicating the formation of the conjugate.

DSC thermograms of CAT3, OA, and OA-CAT3 conjugate are shown in Figure 3C. The DSC thermograms of pure $\mathrm{OA}$ indicated two endothermic peaks at -11.8 and $13.7^{\circ} \mathrm{C}$, respectively, corresponding to the crystal transformation from the $\gamma$-form to $\alpha$-form and the intrinsic melting point of $\alpha$-form [28]. CAT3 crystallinity decreased due to the molecular interaction between CAT3 and OA. 

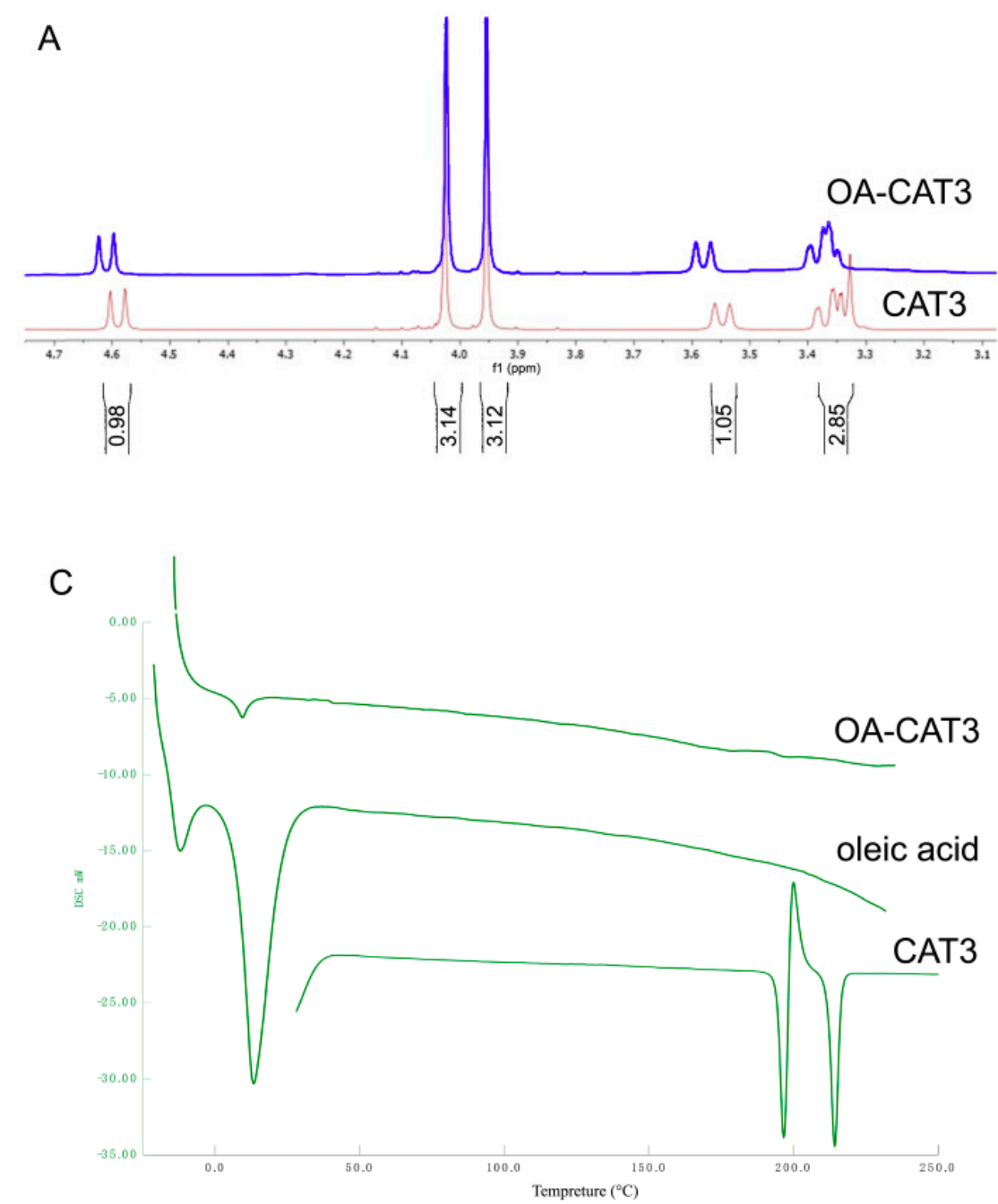

B

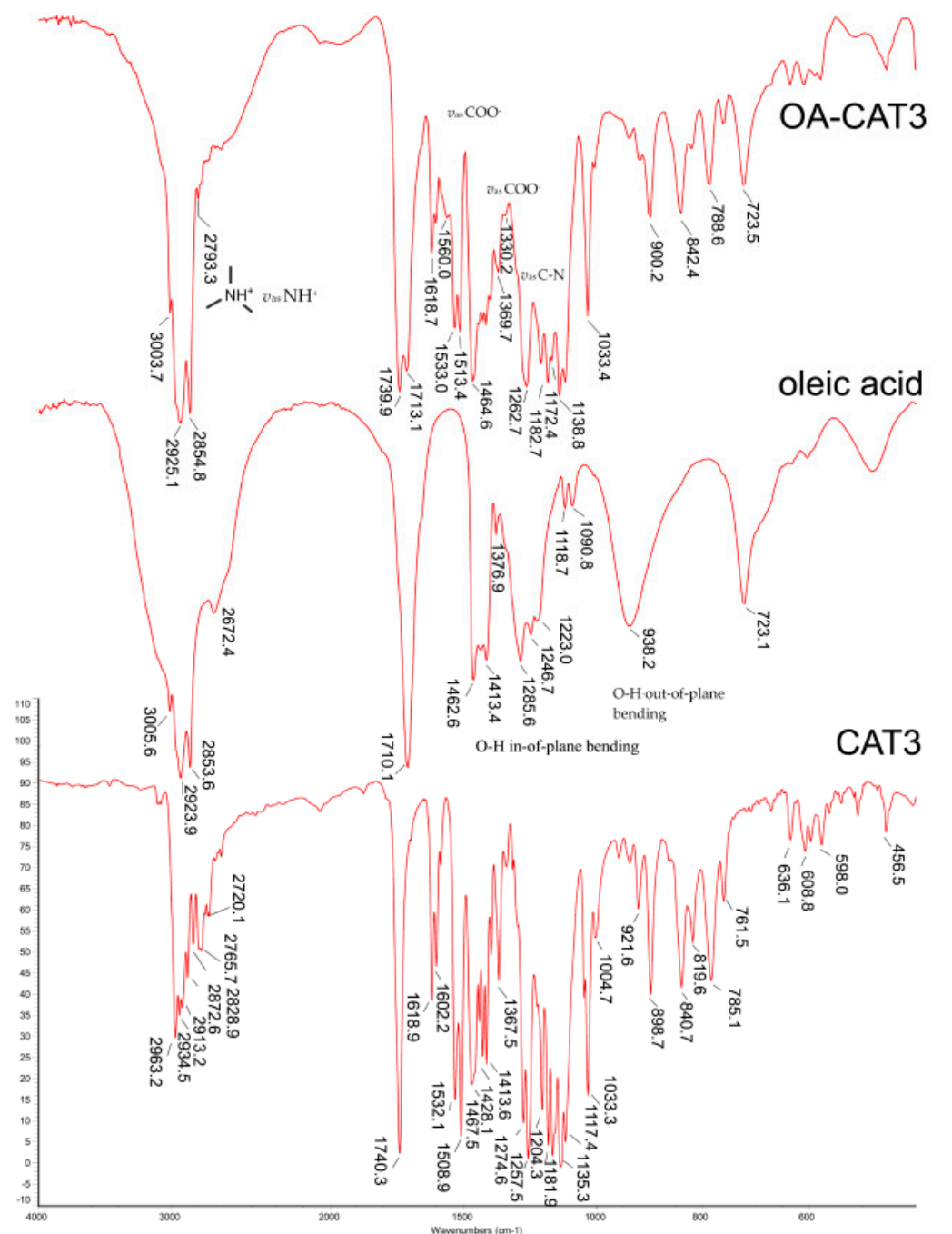

Figure 3. ${ }^{1} \mathrm{H}$ NMR (A), Fourier transform infrared spectroscopy (FTIR) spectra (B), and differential scanning calorimetry (DSC) thermograms (C) of CAT3, oleic acid (OA), and oleic acid and CAT3 conjugate (OA-CAT3). 


\subsection{Characterizations of OA-CAT3-SLN and CAT3-SLN}

\subsubsection{Droplet Size, PDI, Zeta Potential, and Morphology}

Particle size is one of the most important factors of SLN [40-43]. As shown in Table 1, the average particle sizes of the prepared SLN formulations were 139.2 $\pm 2.47,151.3 \pm 17.51$, and $155.7 \pm 3.03 \mathrm{~nm}$ for blank SLN, OA-CAT3-SLN, and CAT3-SLN, respectively. The PDI of all SLN formulations were less than 0.3 , which indicates that the preparations had an ideal and narrow distribution and followed unimodal normal distribution (Figure 4A) [44].

Table 1. Physico-chemical characterization of blank SLN, OA-CAT3-SLN, and CAT3 loaded SLN (CAT3-SLN). $(n=3)$.

\begin{tabular}{cccccc}
\hline Formulation & Particle Size $(\mathbf{n m})$ & PDI & Zeta Potential $(\mathbf{m V})$ & DL $(\%)$ & EE (\%) \\
\hline Blank SLN & $139.2 \pm 2.47$ & $0.257 \pm 0.003$ & $-41.7 \pm 0.80^{* *}$ & $/$ & $/$ \\
OA-CAT3-SLN & $151.3 \pm 17.51$ & $0.230 \pm 0.018$ & $-26.7 \pm 0.46$ & $5.478 \pm 0.346$ & $80.65 \pm 6.79$ \\
CAT3-SLN & $155.7 \pm 3.03$ & $0.228 \pm 0.007$ & $-7.9 \pm 0.15^{* *}$ & $4.067 \pm 0.163 * *$ & $58.48 \pm 3.35^{* *}$ \\
\hline & & $* * p<0.01$ versus OA-CAT3-SLN.
\end{tabular}

A

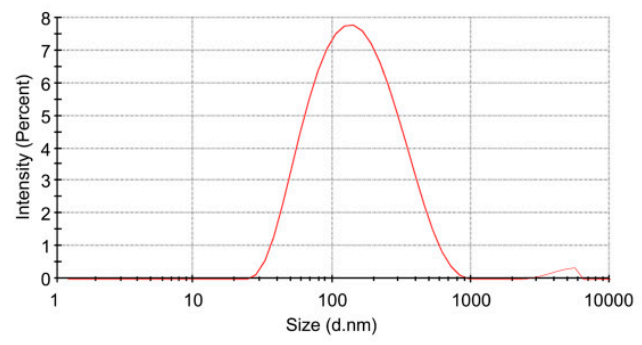

B

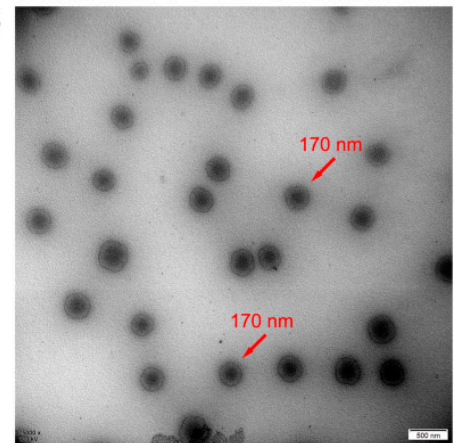

Figure 4. Particle size distribution (A) and transmission electron microscopy (TEM) image (B) of OA-CAT3 loaded solid lipid nanoparticles (SLN) (OA-CAT3-SLN). (Scale bar: $200 \mathrm{~nm}$ ).

The TEM image of OA-CAT3-SLN is shown in Figure 4B, which demonstrate that SLN are spherical in shape with an average size of about $170 \mathrm{~nm}$.

The zeta potential indicates the degree of repulsion between similarly charged, adjacent particles in dispersion, and a higher zeta potential will confer stability and prevent aggregation [45]. Table 1 shows the mean zeta potential of SLN. The zeta potential values of blank SLN, OA-CAT3-SLN, and CAT3-SLN were $-41.7 \pm 0.80 \mathrm{mV},-26.7 \pm 0.46 \mathrm{mV}$, and $-7.9 \pm 0.15 \mathrm{mV}$, respectively.

\subsubsection{Drug Loading (DL) and Encapsulation Efficiency (EE)}

The DL and EE were determined by spectrophotometric analysis at $263 \mathrm{~nm}$. Linear range, repeatability, and recovery were calculated under optimal conditions. To estimate the repeatability, shown as relative standard deviation percentage (\%RSD), six replicates were employed and the \%RSD value was found to be less than $1.0 \%$. Satisfactory recoveries (99.8\%) and low RSD (less than $2.0 \%$ ) were achieved. Good linearity was obtained $\left(r^{2}>0.9999\right)$ in the concentration range of $1-8 \mu \mathrm{g} / \mathrm{mL}$ for CAT3 (Formula (3)). In the formula, $c$ represents the concentration of CAT3 as $\mu \mathrm{g} / \mathrm{mL}$.

$$
\text { Absorbance }=0.1118 \times c+0.0063
$$

Table 1 shows the influence of OA-CAT3 on EE and DL. The EE of OA-CAT3-SLN $(80.65 \pm 6.79 \%)$ was significantly higher than that of CAT3-SLN $(58.48 \pm 3.35 \%)$. A statistically significant difference in the DL of OA-CAT3-SLN was observed compared to that of CAT3-SLN. The DL was $5.478 \pm 0.346 \%$ for OA-CAT3-SLN and $4.067 \pm 0.163 \%$ for CAT3-SLN. 


\subsubsection{In Vitro Controlled Release Study}

Figure 5A shows the accumulative CAT3 release in the dissolution media. In the first $24 \mathrm{~h}$, more than $80 \%$ of CAT3 was released from the CAT3 suspension, conforming to the Higuchi model equation (Formula (4) and Figure 5B). Both OA-CAT3-SLN and CAT3-SLN displayed biphasic drug release patterns, with burst release at the initial stage and prolonged release later. However, OA-CAT3-SLN $(29.84 \pm 8.53 \%)$ exhibited a lower burst release than CAT3-SLN ( $44.1 \pm 5.97 \%)$ and can release completely $(84.08 \pm 7.76 \%)$ versus CAT3-SLN $(73.65 \pm 6.14 \%)$ at $72 \mathrm{~h}$. The lower burst drug release at the initial stage and better release control $[46,47]$ at $72 \mathrm{~h}$ can be achieved by introducing OA-CAT3 conjugates into the formulation. The release profile of OA-CAT3-SLN and CAT3-SLN conformed to the zero-order with the F0 model equation (Formula (5) and Figure 5C) and Weibull model equation (Formula (6) and Figure 5D), respectively. In the formulas, $F$ represents the fraction of drug released in time $t$.

$$
\begin{gathered}
F=20.044 \times t^{1 / 2} \\
F=32.833+0.827 \times t \\
F=100 \times\left(1-e^{-(t-0.292)^{\frac{0.191}{1.633}}}\right)
\end{gathered}
$$

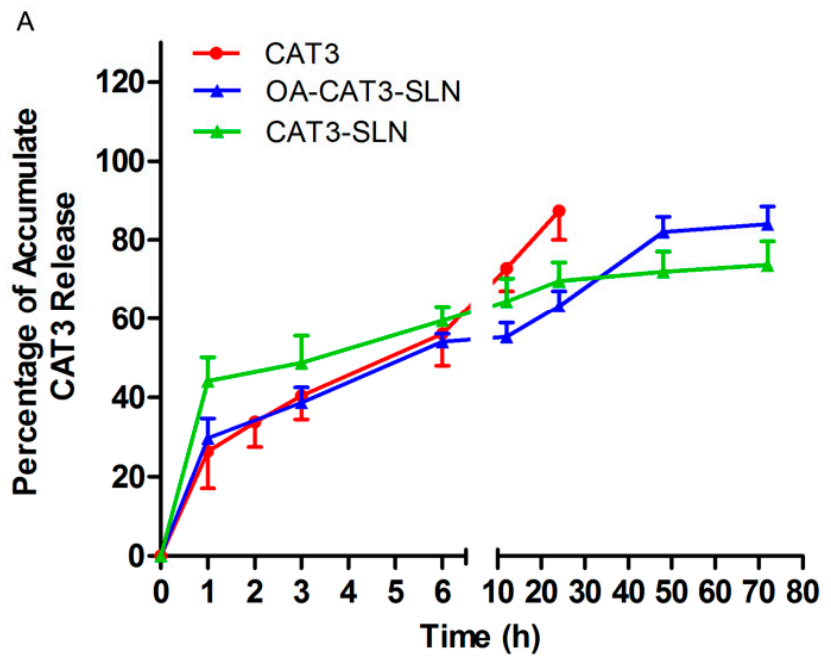

B

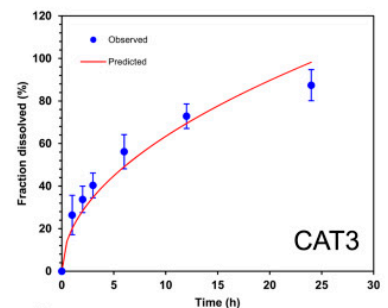

C
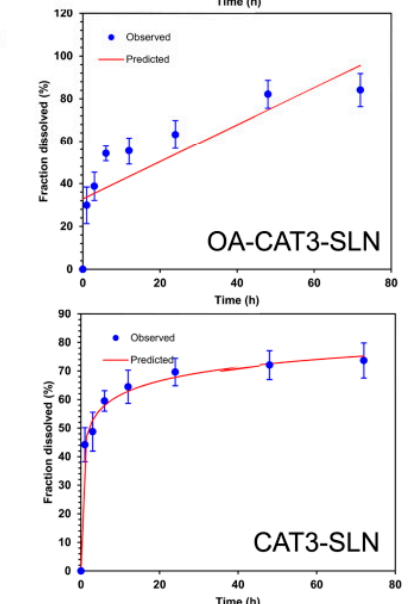

Figure 5. In vitro accumulate drug release percentage versus time of CAT3, OA-CAT3-SLN, and CAT3-SLN (A), Higuchi model of CAT3 suspension release (B), zero-order with the F0 model of OA-CAT3-SLN release (C), and Weibull model of CAT3-SLN release (D).

\subsubsection{Differential Scanning Calorimetry (DSC) and Powder X-ray Diffractometry (PXRD) Studies}

DSC thermograms of CAT3, the physical mixture of CAT3 with blank-SLN, blank-SLN, CAT3-SLN, and OA-CAT3-SLN are shown in Figure 6A. There are two sharp melting endothermic peaks at 195.8 and $213.7^{\circ} \mathrm{C}$ with an enthalpy of 38.5 and $24.6 \mathrm{~J} \cdot \mathrm{g}^{-1}$, respectively, in the CAT3 sample, indicating that the CAT3 was a mixture of two crystal forms. The melting endotherm of blank SLN ranged from 40 to $75^{\circ} \mathrm{C}$, which indicated that the core of the blank SLN was crystalline and solid. The characteristic melting endotherm of CAT3 was observed in the physical mixture samples of the blank SLN and the CAT3, which were 172.0 and $199.1^{\circ} \mathrm{C}$, respectively. From the DSC curve of OA-CAT3-SLN, the melting 
endotherm of CAT3 was not observed, implying that the CAT3 was present in an amorphous state. However, the melting endotherms were at 145.6 and $170.8^{\circ} \mathrm{C}$ in the CAT3-SLN, implying that CAT3 was still partially crystalline in CAT3-SLN.

The PXRD results are shown in Figure 6B. CAT3 was a crystalline substance, with $d$ values of 10.663 , $5.363,5.217,4.002,7.748,3.778,6.094$, and 11.487. There were wide diffraction peaks at $d$ values of 4.229, $21.191,3.865$, and 4.689 in blank SLN, indicating that its lipid core was crystalline. The crystallographic diffraction peaks of blank SLN and CAT3 physical mixture were a simple superposition of the CAT3 and the blank SLN diffraction peaks. The crystalline peaks of CAT3 were absent in the OA-CAT3-SLN sample, indicating that the drugs were in amorphous form. However, the main characteristic diffraction peak of CAT3 at $d$ values of $10.663,5.363$, and 5.217 was found in the CAT3-SLN sample, indicating CAT3 was still in the crystalline form. Consistent with the DSC results, the results of PXRD proved that OA-CAT3 was necessary for the composition of CAT3 loaded SLN to obtain an amorphous drug.

\subsection{In Vitro and In Vivo Bio Evaluation of OA-CAT3-SLN}

\subsubsection{Transepithelial Transport Study}

The transepithelial transport of CAT3 suspension and OA-CAT3-SLN across the MDCK-MDR1 cell monolayer was determined and the results are summarized in Figure 7. CAT3 exhibited a very low $P_{\text {app(AP-BL) }}\left[(0.1056 \pm 0.02888) \times 10^{-6} \mathrm{~cm} \cdot \mathrm{s}^{-1}\right]$ in MDCK-MDR1 cell model at $100 \mathrm{ng} / \mathrm{mL}$. However, the $P_{\text {app(AP-BL) }}$ of OA-CAT3-SLN was $(0.2557 \pm 0.0578) \times 10^{-6} \mathrm{~cm} \cdot \mathrm{s}^{-1}$, which was 2.42 -fold higher than CAT3.

To clarify the mechanisms of enhanced drug transfer mediated by OA-CAT3-SLN, lower temperatures and transfer inhibitors were used to test the $P_{\text {app }}$. When tested at $4{ }^{\circ} \mathrm{C}$, the $P_{\text {app (AP-BL) }}$ of OA-CAT3-SLN $\left[(0.01797 \pm 0.00628) \times 10^{-6} \mathrm{~cm} \cdot \mathrm{s}^{-1}\right]$ was significantly decreased $(p<0.05)$, implying that the cellular uptake OA-CAT3-SLN was energy-dependent [48]. When individually pretreated with the inhibitors chlorpromazine and nystatin, the $P_{\text {app(AP-BL) }}$ of OA-CAT3-SLN was not significantly altered and demonstrated as $(0.2596 \pm 0.03287) \times 10^{-6} \mathrm{~cm} \cdot \mathrm{s}^{-1}$ and $(0.231 \pm 0.05941) \times 10^{-6} \mathrm{~cm} \cdot \mathrm{s}^{-1}$, respectively. However, under the influence of MCYP, the $P_{\text {app(AP-BL) }}$ of OA-CAT3-SLN $\left[(0.1362 \pm 0.0188) \times 10^{-6}\right.$ $\mathrm{cm} \cdot \mathrm{s}^{-1}$ ] was significantly decreased $(p<0.05)$. Therefore, the endocytosis of OA-CAT3-SLN was not a clathrin or caveolin dependent transport but was dependent on cholesterol [49]. 
A

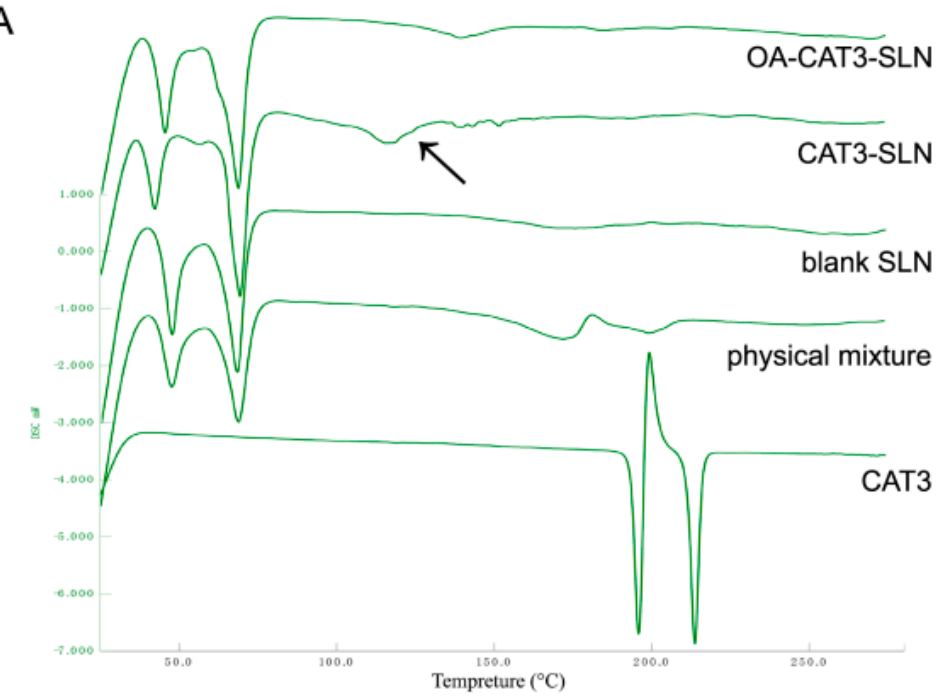

B

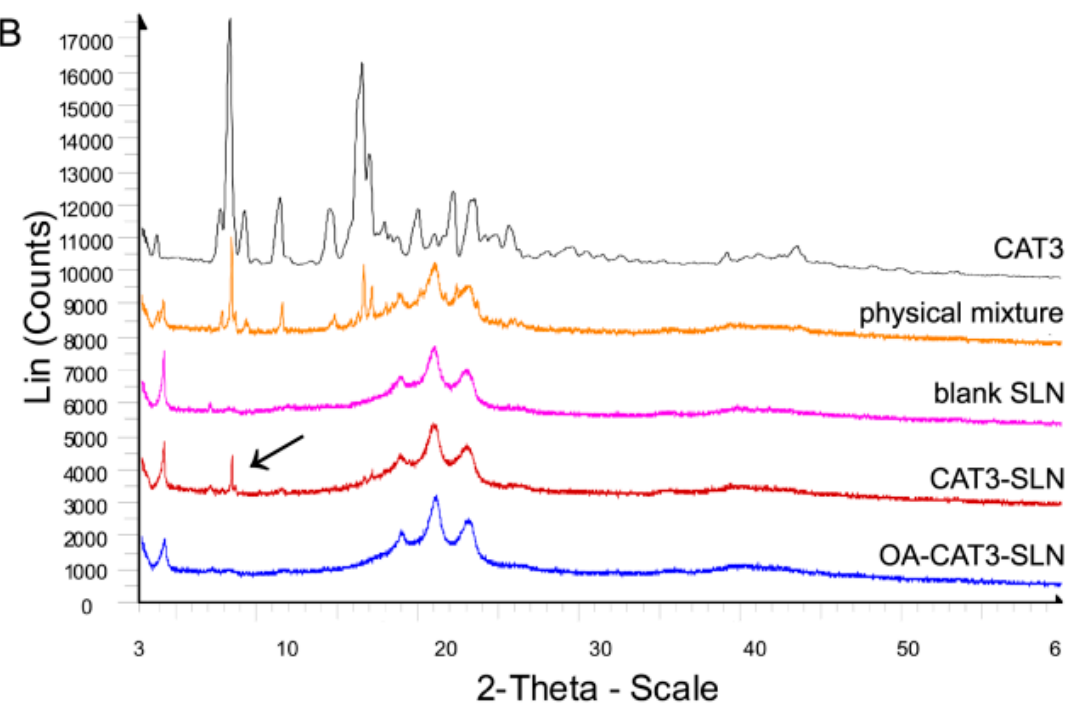

Figure 6. DSC thermograms (A) and powder X-ray diffractometry (PXRD) patterns (B) of lyophilized OA-CAT3-SLN, CAT3-SLN, blank SLN, CAT3, and the physical mixture of blank SLN with CAT3. 


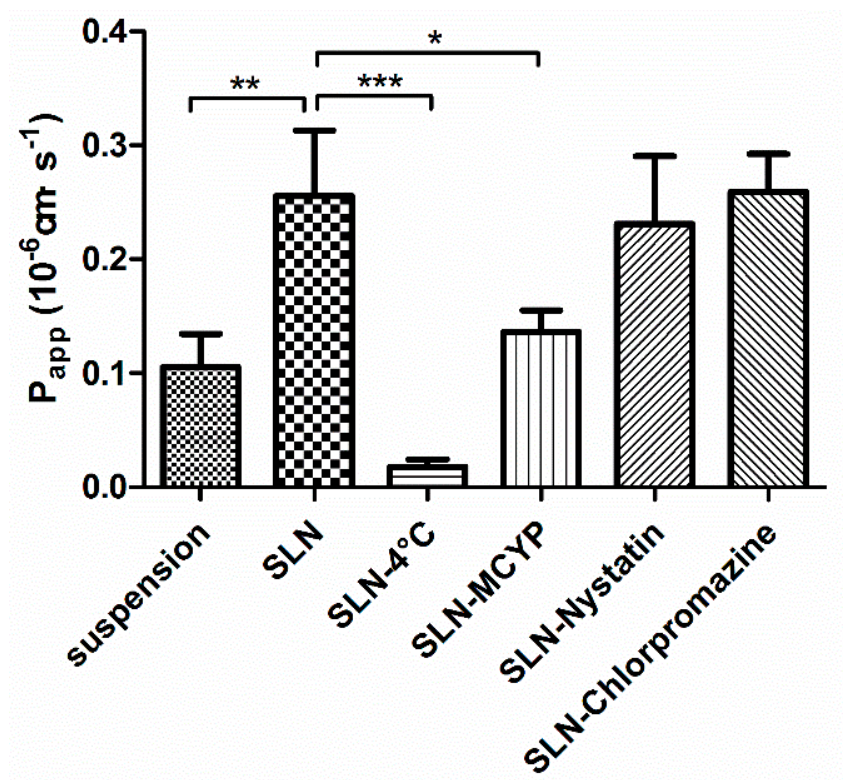

Figure 7. In vitro apparent permeability coefficient $\left(P_{\text {app }}\right)$ of CAT3 suspension and OA-CAT3-SLN after $2 \mathrm{~h}$ of transport across MDCK-MDR1 cell monolayer. $\left({ }^{*} p<0.05,{ }^{* *} p<0.01\right.$; ${ }^{* *} p<0.001$; and $n=3$ ).

\subsubsection{In Vitro Cellular Uptake Study}

The in vitro cellular uptake profile of Cou-6 loaded SLN was qualitatively analyzed by using LSCM. As shown in Figure 8A, the fluorescence intensity of Caco-2 cells incubated with Cou-6 loaded SLN was stronger than that of Cou-6 solution. However, the uptake of Cou-6 loaded SLN was significantly decreased when incubated with the inhibitor MCYP and that of at $4{ }^{\circ} \mathrm{C}$, indicating that the cellular uptake by SLN was a cholesterol- and energy-dependent process. Similar results were observed in C6 cells (Figure 8B).
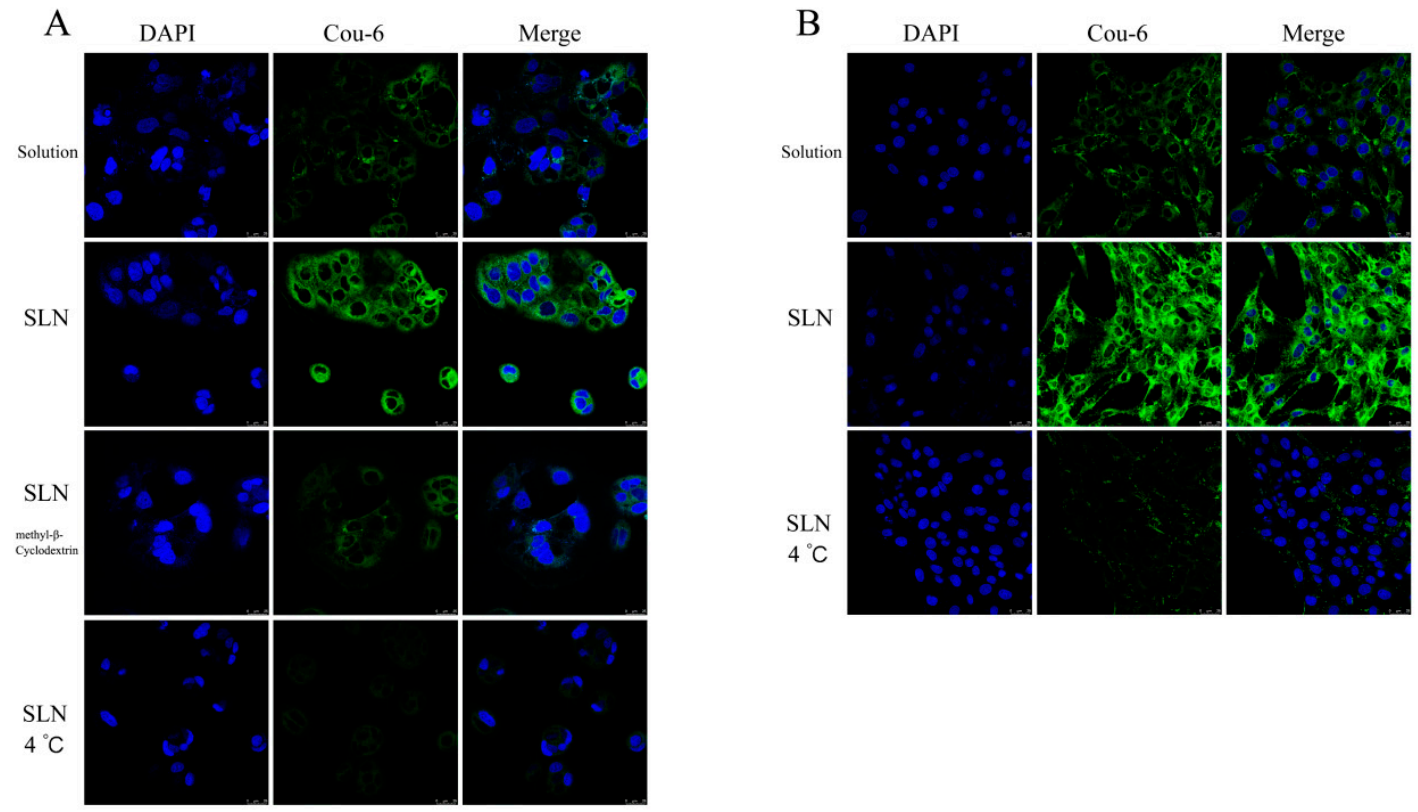

Figure 8. Confocal laser-scanning microscopy of internalization of fluorescent coumarin 6 (Cou-6, green) in Caco-2 (A) and C6 (B) cells after $1 \mathrm{~h}$ of incubation with Cou-6 suspension or Cou-6 loaded SLN (100 ng Cou-6 equivalent/mL). Cell nuclei were stained with 4',6-diamidino-2-phenylindole (DAPI) (blue). (Scale bar: $25 \mu \mathrm{m}$ ). 


\subsubsection{In Vitro Cytotoxicity Analysis}

To compare the cytotoxic differences among the CAT3 suspension, OA-CAT3-SLN, and blank SLN against the $\mathrm{C} 6$ glioma cell line, the in vitro cytotoxicity activity was investigated using the MTT assay. Figure 9 shows the cell viability following 24,48 , and $72 \mathrm{~h}$ of incubation. The results showed that the blank SLN failed to exhibit cytotoxicity in the C6 cells, and the viability was $96.58 \% \pm 4.81 \%$, $91.85 \% \pm 5.00 \%$, and $85.40 \% \pm 5.53 \%$ for 24,48 , and $72 \mathrm{~h}$, respectively, indicating the composition used to formulate SLN was biocompatible and safe in vivo [50]. Furthermore, CAT3 suspension and OA-CAT3-SLN exhibited time-dependent cytotoxicity, implying that the cell viability decreased with a long duration of contact [12]. The viability of OA-CAT3-SLN was $89.68 \% \pm 4.33 \%, 29.77 \% \pm 2.13 \%$, and $10.75 \% \pm 3.12 \%$ for 24,48 , and $72 \mathrm{~h}$, respectively, while the cell viabilities for the CAT3 suspension were $81.15 \% \pm 2.73 \%, 46.20 \% \pm 3.12 \%$, and $16.53 \% \pm 3.95 \%$, respectively. Hence, after 48 and $72 \mathrm{~h}$ of incubation, OA-CAT3-SLN exhibited a stronger in vitro anti-glioma efficacy than the CAT3 suspension.

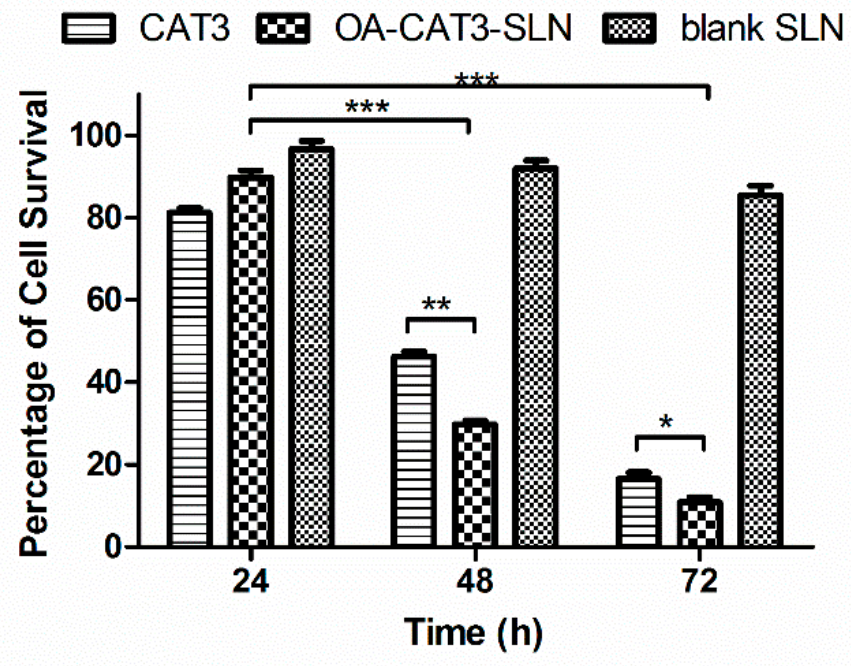

Figure 9. In vitro cytotoxicity evaluation of CAT3 suspension, OA-CAT3-SLN, and blank SLN in C6 glioma cells. $\left({ }^{*} p<0.05,{ }^{* *} p<0.01 ;{ }^{* * *} p<0.001\right.$; and $n=3$ ).

\subsubsection{In Vivo Pharmacokinetic Studies}

In the in vivo pharmacokinetic study, a simple and sensitive validated LC-MS/MS analytical method was used to determine the levels of CAT3 and its active metabolite PF403 in rat plasma, with CAT as the internal standard. Calibration curve in plasma spiked with varying concentrations of CAT3 and PF403 were linear over the concentration range of $0.14-100 \mathrm{ng} / \mathrm{mL}$, with a determination coefficient $>0.99$. The lower limit of quantification was $0.14 \mathrm{ng} / \mathrm{mL}$. Intra- and inter-day variability (RSD) of CAT3 and PF403 in plasma were less than 15\%, and the accuracy was between $95 \%$ and $120 \%$.

The plasma drug concentration versus time curves after the oral administration of CAT3 suspension, OA-CAT3, CAT3-SLN, and OA-CAT3-SLN are shown in Figure 10A (CAT3, as prodrug form) and 10B (PF403, as active metabolite form), and the key pharmacokinetic parameters in plasma are listed in Tables 2 and 3. 
A

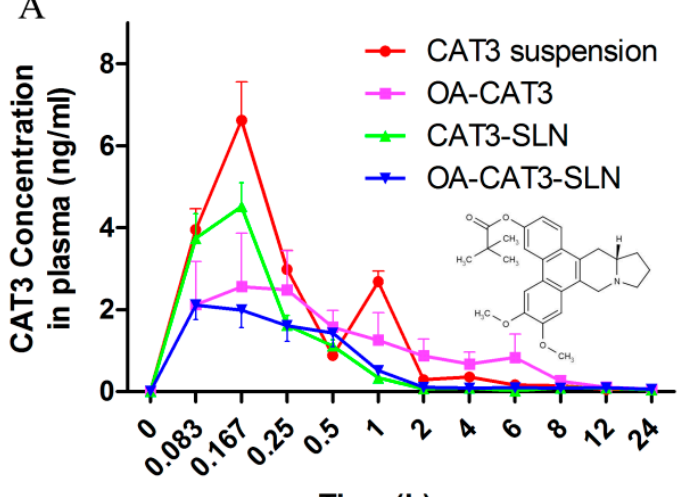

Time (h)
B

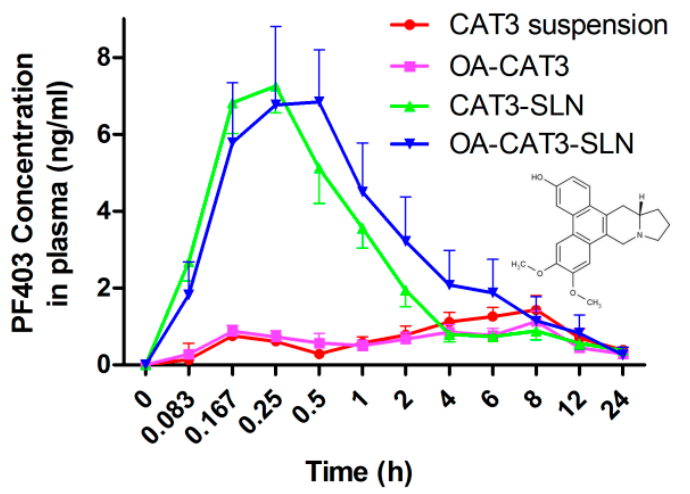

Figure 10. The variation of plasma concentration of CAT3 as the pro-drug form (A) and PF403 as the metabolite (B) in two animal groups as a function of time, after single oral dose administration of CAT3 suspension, OA-CAT3, CAT3-SLN, and OA-CAT3-SLN $(n=6)$.

Table 2. The pharmacokinetic parameters of CAT3 (as the pro-drug form) in rats after oral administration $(n=6)$.

\begin{tabular}{cccccc}
\hline \multicolumn{2}{c}{ Parameters } & CAT3 & OA-CAT3 & CAT3-SLN & OA-CAT3-SLN \\
\hline $\mathrm{AUC}_{(0-t)}$ & $\mathrm{ng} \cdot \mathrm{mL}^{-1} \cdot \mathrm{h}$ & $6.39 \pm 0.645^{* *}$ & $8.632 \pm 3.843^{*}$ & $3.093 \pm 0.133$ & $3.284 \pm 1.254$ \\
$\mathrm{AUC}_{(0-\infty)}$ & $\mathrm{ng} \cdot \mathrm{mL}^{-1} \cdot \mathrm{h}$ & $7.23 \pm 0.476^{* *}$ & $8.954 \pm 3.716^{*}$ & $3.807 \pm 0.441$ & $4.356 \pm 1.562$ \\
$\mathrm{MRT}_{(0-t)}$ & $\mathrm{H}$ & $3.887 \pm 0.805$ & $5.113 \pm 0.616$ & $5.433 \pm 0.82$ & $6.158 \pm 0.704$ \\
$\mathrm{MRT}_{(0-\infty)}$ & $\mathrm{H}$ & $8.779 \pm 6.346$ & $6.48 \pm 2.444$ & $13.954 \pm 6.912$ & $16.604 \pm 2.597$ \\
$t_{1 / 2 z}$ & $\mathrm{H}$ & $10.824 \pm 6.769$ & $4.754 \pm 3.951$ & $16.742 \pm 11.915$ & $16.902 \pm 1.578$ \\
$T_{\max }$ & $\mathrm{H}$ & $0.167 \pm 0$ & $0.25 \pm 0.129$ & $0.153 \pm 0.034$ & $0.125 \pm 0.07$ \\
$\mathrm{Vz} / \mathrm{F}$ & $\mathrm{L} / \mathrm{kg}$ & $21,169.855 \pm 12,087.293$ & $8806.657 \pm 8572.706$ & $62,090.614 \pm 42,268.807$ & $61,307.763 \pm 18,523.656$ \\
$\mathrm{CLz} / \mathrm{F}$ & $\mathrm{L} / \mathrm{h} / \mathrm{kg}$ & $1388.185 \pm 91.525$ & $1268.605 \pm 450.993$ & $2653.874 \pm 278.551$ & $2576.094 \pm 1027.274$ \\
$C_{\max }$ & $\mathrm{ng} / \mathrm{mL}$ & $6.618 \pm 0.942 * *$ & $2.711 \pm 1.201$ & $4.539 \pm 1.406 * *$ & $2.245 \pm 0.951$ \\
\hline \multicolumn{7}{c}{$* p<0.05, * * p<0.01$ versus OA-CAT3-SLN. }
\end{tabular}

Table 3. The pharmacokinetic parameters of PF403 (as the metabolite) in rats after oral administration $(n=6)$.

\begin{tabular}{cccccc}
\hline \multicolumn{2}{c}{ Parameters } & CAT3 & OA-CAT3 & CAT3-SLN & OA-CAT3-SLN \\
\hline $\mathrm{AUC}_{(0-t)}$ & $\mathrm{ng} \cdot \mathrm{mL}^{-1} \cdot \mathrm{h}$ & $18.778 \pm 1.953^{*}$ & $13.713 \pm 5.616^{*}$ & $21.723 \pm 6.763 *$ & $32.045 \pm 7.425$ \\
$\mathrm{AUC}_{(0-\infty)}$ & $\mathrm{ng} \cdot \mathrm{mL}^{-1} \cdot \mathrm{h}$ & $24.42 \pm 2.435 *$ & $30.861 \pm 24.886$ & $25.541 \pm 9.898 *$ & $34.73 \pm 6.178$ \\
$\mathrm{MRT}_{(0-t)}$ & $\mathrm{H}$ & $9.775 \pm 0.104$ & $9.677 \pm 1.252$ & $6.649 \pm 1.068$ & $5.945 \pm 0.889$ \\
$\mathrm{MRT}_{(0-\infty)}$ & $\mathrm{H}$ & $16.449 \pm 0.87$ & $56.077 \pm 75.093$ & $10.837 \pm 4.978$ & $7.742 \pm 1.978$ \\
$t_{1 / 2 \mathrm{z}}$ & $\mathrm{H}$ & $10.121 \pm 0.759$ & $39.049 \pm 53.163$ & $8.94 \pm 3.181$ & $6.218 \pm 1.528$ \\
$T_{\mathrm{max}}$ & $\mathrm{H}$ & $8 \pm 0$ & $4.736 \pm 3.834$ & $0.264 \pm 0.123$ & $0.417 \pm 0.129$ \\
$\mathrm{Vz} / \mathrm{F}$ & $\mathrm{L} / \mathrm{kg}$ & $6011.79 \pm 535.387$ & $15,412.451 \pm 13,804.038$ & $5298.387 \pm 1424.022$ & $2807.484 \pm 748.904$ \\
$\mathrm{CLz} / \mathrm{F}$ & $\mathrm{L} / \mathrm{h} / \mathrm{kg}$ & $412.919 \pm 41.283$ & $442.039 \pm 193.353$ & $439.687 \pm 152.452$ & $333.068 \pm 131.27$ \\
$C_{\text {max }}$ & $\mathrm{ng} / \mathrm{mL}$ & $1.429 \pm 0.171 * *$ & $1.431 \pm 0.315 * *$ & $7.884 \pm 1.621$ & $7.36 \pm 1.694$ \\
\hline \multicolumn{7}{c}{} & $* p<0.05, * * p<0.01$ versus OA-CAT3-SLN. &
\end{tabular}

In Figure 10A, a double absorption peak of CAT3, as the pro-drug form in the plasma, was observed after the administration of CAT3 suspension, and the $\mathrm{AUC}_{0 \sim t}$ was $6.39 \pm 0.645 \mathrm{ng} \cdot \mathrm{mL}^{-1} \cdot \mathrm{h}$. In addition, the $\mathrm{AUC}_{0 \sim t}$ of CAT3 after administering OA-CAT3-SLN was $3.284 \pm 1.254 \mathrm{ng} \cdot \mathrm{mL}^{-1} \cdot \mathrm{h}$, which was less in plasma than in the CAT3 suspension, implying the presence of greater CAT3 pro-drug transfer to its active metabolite. The $\mathrm{AUC}_{0 \sim t}$ of PF403, the metabolite form in plasma, following treatment with OA-CAT3-SLN $\left(32.045 \pm 7.425 \mathrm{ng} \cdot \mathrm{mL}^{-1} \cdot \mathrm{h}\right)$ was 1.7 -fold higher than that following treatment with the CAT3 suspension $\left(18.778 \pm 1.953 \mathrm{ng} \cdot \mathrm{mL}^{-1} \cdot \mathrm{h}\right)$. Similar to the trend observed for AUC $_{0 \sim t}$ of PF403, the $C_{\max }$ of PF403 of OA-CAT3-SLN $(7.36 \pm 1.694 \mathrm{ng} / \mathrm{mL})$ was 5.5-fold higher than in those treated with the CAT3 suspension $(1.429 \pm 0.171 \mathrm{ng} / \mathrm{mL})$. Moreover, OA-CAT3-SLN significantly increased the $\mathrm{AUC}_{0 \sim t}$ of PF403, compared with OA-CAT3 (13.713 \pm 5.616) and CAT3-SLN (21.723 \pm 
6.763) groups, which shows that both OA-CAT3 and SLN have important roles in promoting absorption. Since the in vitro antitumor activity of PF403 is about 1000 times greater than that the pro-drug CAT3 and PF403 can penetrate the blood-brain barrier and incur an anti-glioma effects [12], the increased bioavailability and $C_{\max }$ of PF403, that were obtained through the oral administration OA-CAT3-SLN, would significantly contribute in exerting a better anti-glioma effect.

\section{Discussion}

Compritol 888 ATO is a natural glyceryl behenate with a number of benefits and usually used as a control release agent, or to improve the heat stability of emulsions [51-53]. Since the chemical stability between CAT3 and Compritol 888 ATO was superior, it was selected for formulation development. Furthermore, for the melting point of Compritol 888 ATO is not extremely high $\left(69-74{ }^{\circ} \mathrm{C}\right)$, so the optimized particle size of OA-CAT3-SLN and CAT3-SLN were only about $150 \mathrm{~nm}$ [54].

The blank SLN, OA-CAT3-SLN, and CAT3-SLN all showed negative zeta potential values due to the carboxyl structure in the OA molecule. However, the OA-CAT3-SLN and CAT3-SLN showed a relatively slightly negative surface charge, which may be attributed to the tertiary nitrogen structure in the CAT3 molecule resisting the negative charge. Furthermore, the OA-CAT3-SLN demonstrated lower zeta potential values than the CAT3-SLN, which may indicate that OA-CAT3 has a higher solubility and was mainly in the lipid core of OA-CAT3-SLN that has less effects on the zeta potential. However, the free CAT3 in the CAT3-SLN was more likely absorbed on the lipid core surface and strongly blocked the negative charge. Hence, the OA-CAT3-SLN will have better physical stability than CAT3-SLN since it has a higher surface charge to prevent aggregation [55]. The surfactants (Tween 80 and Poloxamer 188), which are neutrally charged, were adsorbed on the particle surface and had a weak influence on zeta potential value.

The DSC results show that the melting endotherm of the lipid core in blank SLN, OA-CAT3-SLN, and CAT3-SLN was reduced from $40-75^{\circ} \mathrm{C}$ compared to the melting point of Compritol 888 ATO $\left(69-74{ }^{\circ} \mathrm{C}\right)$, implying that the OA can prolong the drug release from SLN [56]. Furthermore, the reduced melting points proved that the perfect crystal lattice of the Compritol 888 ATO lipid core was altered when OA was incorporated [25]. Hence, the SLN which contains OA would have higher accommodation capacity for CAT3. Moreover, there were differences in the maximum DL that was loaded on the OA-CAT3-SLN and CAT3-SLN.

A reduction in the melting point of CAT3 in the physical mixture samples of blank SLN and the CAT3 was observed in the DSC thermograms compared to that of pure CAT3. This was because the DSC results were obtained during the warming up of the environment. While the temperature was being increased, CAT3 would partly have been dissolved in the melting lipids, decreasing the melting points.

Both the PXRD and DSC results for OA-CAT3-SLN and CAT3-SLN indicated that CAT3 was present in crystalline form in CAT3-SLN, but in amorphous form in OA-CAT3-SLN. The possible reason for this phenomenon could be attributed to CAT3 demonstrating higher solubility in lipids after forming OA-CAT3, and due to the stable presentation in the lipid core, ensuring less precipitate during the cooling process of the OA-CAT3-SLN formulation. However, during the cooling process of the CAT3-SLN, the free drugs cannot acquire enough solubility in lipids if not conjugated to OA, indicating that the oversaturated drugs in aqueous phase will precipitate out and crystallize, getting absorbed on the lipid surface owing to the hydrophobic nature [57]. The inconsistent location of CAT3 in the lipid core of OA-CAT3-SLN and CAT3-SLN resulted in the differences in the in vitro drug release and EE. Lower burst drug release and higher EE were observed with OA-CAT3-SLN than with CAT3-SLN.

The CAT (Figure 1C), which is isolated from the roots of Tylophora atrofolliculata and Tylophora ovate [58], was selected as the best ISTD to test the concentration of CAT3 and PF403 in the plasma owing to its similar molecular structure and comparable pKa with CAT3 and PF403, and as it would not generate in plasma either from CAT3 nor PF403. 
Since PF403 was the substrate of P-gp and had poor bioavailability, it could not have reached sufficiently high plasma concentrations and enter into the brain tissue to exhibit anti-glioma effects in vivo after oral administration $[12,58]$. Through the use of OA-CAT3-SLN, the in vitro cellular uptake and transepithelial transport were increased significantly, promoting more CAT3 conversion into PF403 in plasma, and higher bioavailability and $C_{\max }$ of PF403, which allowed a higher drug concentration to accumulate in the brain tissue to demonstrate enhanced anti-glioma effect.

\section{Conclusions}

The novel OA-CAT3 conjugate that has been synthesized for the first time, increased the solubility of CAT3 in lipids and was used to constructed OA-CAT3-SLN, which encapsulated amorphous drugs and had higher EE. OA-CAT3-SLN was more easily taken up by the intestinal epithelial cells in an energy-dependent cholesterol-mediated manner, resulting in higher monolayer membrane permeability. In vivo pharmacokinetic results showed that OA-CAT3-SLN can greatly increase the bioavailability and $C_{\max }$ of its active metabolites in plasma, which could promote the anti-glioma effects in vivo. More studies will be tested in the future within orthotopic glioma models to test the anti-tumor effects of OA-CAT3-SLN.

Author Contributions: Conceptualization, H.W.; Funding acquisition, Y.L.; Methodology, H.W., L.L., R.W. (Renyun Wang), J.H., Y.W., Y.Y. and Y.G.; Project administration, L.G.; Supervision, W.D.; Writing-original draft, H.W.; Writing-review \& editing, J.Y., R.W. (Rubing Wang), and X.X. All authors have read and agreed to the published version of the manuscript.

Funding: This work was financially supported by the National Drug Innovation Major Project (2018ZX09711001-002-005) and the Peking Union Medical College Youth Innovation Fund (2017350020).

Conflicts of Interest: The authors declare no conflicts of interest in this work.

\section{Abbreviations}

$\begin{array}{ll}\text { CAT3 } & \text { 13a-(S)-3-pivaloyloxyl-6,7-dimethoxyphenanthro(9,10-b)-indolizidine } \\ \text { PF403 } & \text { 13a-(S)-3-hydroxyl-6,7-dimethoxyphenanthro(9,10-b)-indolizidine } \\ \text { GBM } & \text { Glioblastoma multiforme } \\ \text { TMZ } & \text { Temozolomide } \\ \text { SLN } & \text { Solid lipid nanoparticles } \\ \text { MDCK-MDR1 } & \text { Madin-Darby canine kidney cells transfected with the human MDR1 gene } \\ \text { SD } & \text { Sprague-Dawley } \\ \text { NMR } & \text { Nuclear magnetic resonance } \\ \text { TMS } & \text { Tetramethylsilane } \\ \text { DL } & \text { Drug loading } \\ \text { EE } & \text { Encapsulation efficiency } \\ \text { OA } & \text { Oleic acid } \\ \text { OA-CAT3 } & \text { Oleic acid and CAT3 conjugate } \\ \text { OA-CAT3-SLN } & \text { OA-CAT3 loaded SLN } \\ \text { CAT3-SLN } & \text { With the same composition and contents to the OA-CAT3-SLN except the preparation of } \\ \text { DSC } & \text { OA-CAT3 in advance } \\ \text { FTIR } & \text { Differential scanning calorimetry } \\ \text { API } & \text { Fourier transform infrared spectroscopy } \\ \text { PVDF } & \text { Active pharmaceutical ingredient } \\ \text { TEER } & \text { Polyvinylidene fluoride } \\ \text { DI } & \text { Transepithelial electrical resistance } \\ \text { PDI } & \text { Deionized } \\ \text { HBSS } & \text { Polydispersity index } \\ \text { AP } & \text { Hanks' balanced salt solution } \\ \text { BL } & \text { Apical side } \\ & \text { Basolateral } \\ \end{array}$




$\begin{array}{ll}\text { LC-MS/MS } & \text { Liquid chromatography-mass spectrometry } \\ P_{\text {app }} & \text { Apparent permeability coefficient } \\ \text { HPLC } & \text { High-performance liquid chromatography } \\ \text { C6-luc } & \text { Luciferase-expressing C6 cells } \\ \text { DAPI } & \text { 4',6-diamidino-2-phenylindole }^{\prime} \\ \text { LSCM } & \text { laser scanning confocal microscopy } \\ \text { MTT } & \text { 3-(4, 5-dimethylthiazol-2-yl)-2,5 diphenyltetrazolium bromide } \\ \text { MCYP } & \text { Methyl- } \beta \text {-Cyclodextrin } \\ \text { PBS } & \text { Phosphate-buffered saline } \\ \text { Cou-6 } & \text { Fluorescent Coumarin 6 } \\ \text { ISTD } & \text { Internal standard } \\ \text { DAS } & \text { Drug and Statistics }\end{array}$

\section{References}

1. Alifieris, C.; Trafalis, D.T. Glioblastoma multiforme: Pathogenesis and treatment. Pharmacol. Ther. 2015, 152, 63-82. [CrossRef] [PubMed]

2. DeAngelis, L.M. Brain tumors. N. Engl. J. Med. 2001, 344, 114-123. [CrossRef] [PubMed]

3. Yan, Y.; Xu, Z.; Dai, S.; Qian, L.; Sun, L.; Gong, Z. Targeting autophagy to sensitive glioma to temozolomide treatment. J. Exp. Clin. Cancer Res. 2016, 35, 23. [CrossRef] [PubMed]

4. Nabors, L.B.; Portnow, J.; Ammirati, M.; Baehring, J.; Brem, H.; Brown, P.; Butowski, N.; Chamberlain, M.C.; Fenstermaker, R.A.; Friedman, A.; et al. Central nervous system cancers, version 1.2015. J. Natl. Compr. Cancer Netw. 2015, 13, 1191-1202. [CrossRef]

5. Alonso, M.M.; Gomez-Manzano, C.; Bekele, B.N.; Yung, W.A.; Fueyo, J. Adenovirus-based strategies overcome temozolomide resistance by silencing the O6-methylguanine-DNA methyltransferase promoter. Cancer Res. 2007, 67, 11499-11504. [CrossRef]

6. Lee, S.Y. Temozolomide resistance in glioblastoma multiforme. Genes Dis. 2016, 3, 198-210. [CrossRef]

7. Banelli, B.; Carra, E.; Barbieri, F.; Würth, R.; Parodi, F.; Pattarozzi, A.; Carosio, R.; Forlani, A.; Allemanni, G.; Marubbi, D. The histone demethylase KDM5A is a key factor for the resistance to temozolomide in glioblastoma. Cell Cycle 2015, 14, 3418-3429. [CrossRef]

8. Ji, M.; Wang, L.; Chen, J.; Xue, N.; Wang, C.; Lai, F.; Wang, R.; Yu, S.; Jin, J.; Chen, X. CAT3, a prodrug of 13a (S)-3-hydroxyl-6, 7-dimethoxyphenanthro [9, 10-b]-indolizidine, circumvents temozolomide-resistant glioblastoma via the Hedgehog signaling pathway, independently of O6-methylguanine DNA methyltransferase expression. Oncotargets Ther. 2018, 11, 3671. [CrossRef]

9. Liu, Z.; Lv, H.; Li, H.; Zhang, Y.; Zhang, H.; Su, F.; Xu, S.; Li, Y.; Si, Y.; Yu, S.; et al. Interaction studies of an anticancer alkaloid, (+)-(13aS)-deoxytylophorinine, with calf thymus DNA and four repeated double-helical DNAs. Chemotherapy 2011, 57, 310-320. [CrossRef]

10. Chen, J.; Lv, H.; Hu, J.; Ji, M.; Xue, N.; Li, C.; Ma, S.; Zhou, Q.; Lin, B.; Li, Y. CAT3, a novel agent for medulloblastoma and glioblastoma treatment, inhibits tumor growth by disrupting the Hedgehog signaling pathway. Cancer Lett. 2016, 381, 391-403. [CrossRef]

11. Lv, H.; Ren, J.; Ma, S.; Xu, S.; Qu, J.; Liu, Z.; Zhou, Q.; Chen, X.; Yu, S. Synthesis, biological evaluation and mechanism studies of deoxytylophorinine and its derivatives as potential anticancer agents. PLOS ONE 2012, 7, e30342. [CrossRef] [PubMed]

12. Li, C.; Li, Y.; Lv, H.; Li, S.; Tang, K.; Zhou, W.; Yu, S.; Chen, X. The novel anti-neuroblastoma agent PF403, inhibits proliferation and invasion in vitro and in brain xenografts. Int. J. Oncol. 2015, 47, 179-187. [CrossRef] [PubMed]

13. Tian, Y.; He, J.; Zhang, R.; Lv, H.; Ma, S.; Chen, Y.; Yu, S.; Chen, X.; Wu, Y.; He, W.; et al. Integrated rapid resolution liquid chromatography-tandem mass spectrometric approach for screening and identification of metabolites of the potential anticancer agent 3,6,7-trimethoxyphenanthroindolizidine in rat urine. Anal. Chim. Acta 2012, 731, 60-67. [CrossRef] [PubMed]

14. Yu, P.; Lv, H.; Li, C.; Ren, J.; Ma, S.; Xu, S.; Chen, X.; Yu, S. Stereospecific Synthesis and Biological Evaluation of Monodesmethyl Metabolites of (+)-13a-(S)-Deoxytylophorinine as Potential Antitumor Agents. Synthesis 2012, 44, 3757-3764. [CrossRef] 
15. Shen, M.-Y.; Liu, T.-I.; Yu, T.-W.; Kv, R.; Chiang, W.-H.; Tsai, Y.-C.; Chen, H.-H.; Lin, S.-C.; Chiu, H.-C. Hierarchically targetable polysaccharide-coated solid lipid nanoparticles as an oral chemo/thermotherapy delivery system for local treatment of colon cancer. Biomaterials 2019, 197, 86-100. [CrossRef]

16. Naseri, N.; Valizadeh, H.; Zakeri-Milani, P. Solid lipid nanoparticles and nanostructured lipid carriers: Structure, preparation and application. Adv. Pharm. Bull. 2015, 5, 305. [CrossRef]

17. Muchow, M.; Maincent, P.; Müller, R.H. Lipid nanoparticles with a solid matrix (SLN $\left.{ }^{\circledR}, \mathrm{NLC}^{\circledR}, \operatorname{LDC}^{\circledR}\right)$ for oral drug delivery. Drug Dev. Ind. Pharm. 2008, 34, 1394-1405. [CrossRef]

18. Schwarz, C. Solid lipid nanoparticles (SLN) for controlled drug delivery II. Drug incorporation and physicochemical characterization. J. Microencapsul. 1999, 16, 205-213. [CrossRef]

19. Dudhipala, N.; Veerabrahma, K. Candesartan cilexetil loaded solid lipid nanoparticles for oral delivery: Characterization, pharmacokinetic and pharmacodynamic evaluation. Drug Deliv. 2016, 23, 395-404. [CrossRef]

20. Manjunath, K.; Venkateswarlu, V. Pharmacokinetics, tissue distribution and bioavailability of clozapine solid lipid nanoparticles after intravenous and intraduodenal administration. J. Control. Release 2005, 107, $215-228$. [CrossRef]

21. Sahu, P.K.; Mishra, D.K.; Jain, N.; Rajoriya, V.; Jain, A.K. Mannosylated solid lipid nanoparticles for lung-targeted delivery of Paclitaxel. Drug Dev. Ind. Pharm. 2015, 41, 640-649. [CrossRef] [PubMed]

22. Xu, Z.; Chen, L.; Gu, W.; Gao, Y.; Lin, L.; Zhang, Z.; Xi, Y.; Li, Y. The performance of docetaxel-loaded solid lipid nanoparticles targeted to hepatocellular carcinoma. Biomaterials 2009, 30, 226-232. [CrossRef] [PubMed]

23. Dudhipala, N.; Janga, K.Y.; Gorre, T. Comparative study of nisoldipine-loaded nanostructured lipid carriers and solid lipid nanoparticles for oral delivery: Preparation, characterization, permeation and pharmacokinetic evaluation. Artif. Cells Nanomed. Biotechnol. 2018, 46, 616-625. [CrossRef] [PubMed]

24. Müller, R.; Runge, S.; Ravelli, V.; Mehnert, W.; Thünemann, A.F.; Souto, E. Oral bioavailability of cyclosporine: Solid lipid nanoparticles (SLN $\left.{ }^{\circledR}\right)$ versus drug nanocrystals. Int. J. Pharm. 2006, 317, 82-89. [CrossRef] [PubMed]

25. Rehman, M.; Asadullah Madni, A.I.; Khan, W.S.; Khan, M.I.; Mahmood, M.A.; Ashfaq, M.; Bajwa, S.Z.; Shakir, I. Solid and liquid lipid-based binary solid lipid nanoparticles of diacerein: In vitro evaluation of sustained release, simultaneous loading of gold nanoparticles, and potential thermoresponsive behavior. Int. J. Nanomed. 2015, 10, 2805. [CrossRef] [PubMed]

26. Müller, R.H.; Radtke, M.; Wissing, S.A. Solid lipid nanoparticles (SLN) and nanostructured lipid carriers (NLC) in cosmetic and dermatological preparations. Adv. Drug Deliv. Rev. 2002, 54, S131-S155. [CrossRef]

27. Almeida, E.D.P.; Dipieri, L.V.; Rossetti, F.C.; Marchetti, J.M.; Bentley, M.V.L.; Nunes, R.D.S.; Sarmento, V.H.V.; Valerio, M.E.G.; Júnior, J.J.R.; Montalvão, M.M. Skin permeation, biocompatibility and antitumor effect of chloroaluminum phthalocyanine associated to oleic acid in lipid nanoparticles. Photodiagnosis Photodyn. Ther. 2018, 24, 262-273. [CrossRef]

28. Inoue, T.; Hisatsugu, Y.; Yamamoto, R.; Suzuki, M. Solid-liquid phase behavior of binary fatty acid mixtures: 1. Oleic acid/stearic acid and oleic acid/behenic acid mixtures. Chem. Phys. Lipids 2004, 127, 143-152. [CrossRef]

29. Makwana, V.; Jain, R.; Patel, K.; Nivsarkar, M.; Joshi, A. Solid lipid nanoparticles (SLN) of Efavirenz as lymph targeting drug delivery system: Elucidation of mechanism of uptake using chylomicron flow blocking approach. Int. J. Pharm. 2015, 495, 439-446. [CrossRef]

30. Venkateswarlu, V.; Manjunath, K. Preparation, characterization and in vitro release kinetics of clozapine solid lipid nanoparticles. J. Control. Release 2004, 95, 627-638. [CrossRef]

31. Kumar, V.V.; Chandrasekar, D.; Ramakrishna, S.; Kishan, V.; Rao, Y.M.; Diwan, P.V. Development and evaluation of nitrendipine loaded solid lipid nanoparticles: Influence of wax and glyceride lipids on plasma pharmacokinetics. Int. J. Pharm. 2007, 335, 167-175. [CrossRef] [PubMed]

32. Dolatabadi, J.E.N.; Hamishehkar, H.; Eskandani, M.; Valizadeh, H. Formulation, characterization and cytotoxicity studies of alendronate sodium-loaded solid lipid nanoparticles. Colloids Surf. B Biointerfaces 2014, 117, 21-28. [CrossRef] [PubMed]

33. Zuo, J.; Gao, Y.; Bouchacra, N.; Löbenberg, R. Evaluation of the DDSolver Software Applications. BioMed Res. Int. 2014, 2014, 204925. [CrossRef] [PubMed]

34. Zhang, Y.; Huo, M.; Zhou, J.; Zou, A.; Li, W.; Yao, C.; Xie, S. DDSolver: An add-in program for modeling and comparison of drug dissolution profiles. AAPS J. 2010, 12, 263-271. [CrossRef] 
35. Yuan, H.; Chen, C.-Y.; Chai, G.-H.; Du, Y.-Z.; Hu, F.-Q. Improved transport and absorption through gastrointestinal tract by PEGylated solid lipid nanoparticles. Mol. Pharm. 2013, 10, 1865-1873. [CrossRef]

36. Hu, Q.; Luo, Y. Recent advances of polysaccharide-based nanoparticles for oral insulin delivery. Int. J. Biol. Macromol. 2018, 120, 775-782. [CrossRef]

37. Wu, L.; Liu, M.; Shan, W.; Cui, Y.; Zhang, Z.; Huang, Y. Lipid nanovehicles with adjustable surface properties for overcoming multiple barriers simultaneously in oral administration. Int. J. Pharm. 2017, 520, $216-227$. [CrossRef]

38. Teskač, K.; Kristl, J. The evidence for solid lipid nanoparticles mediated cell uptake of resveratrol. Int. J. Pharm. 2010, 390, 61-69. [CrossRef]

39. Han, S.; Kwon, S.; Jeong, Y.; Yu, E.; Park, S. Physical characterization and in vitro skin permeation of solid lipid nanoparticles for transdermal delivery of quercetin. Int. J. Cosmet. Sci. 2014, 36, 588-597. [CrossRef]

40. Kang, B.K.; Lee, J.S.; Chon, S.K.; Jeong, S.Y.; Yuk, S.H.; Khang, G.; Lee, H.B.; Cho, S.H. Development of self-microemulsifying drug delivery systems (SMEDDS) for oral bioavailability enhancement of simvastatin in beagle dogs. Int. J. Pharm. 2004, 274, 65-73. [CrossRef]

41. Acosta, E. Bioavailability of nanoparticles in nutrient and nutraceutical delivery. Curr. Opin. Colloid Interface Sci. 2009, 14, 3-15. [CrossRef]

42. Lingling, G.; Yuan, Z.; Weigen, L. Preparation, optimization, characterization and in vivo pharmacokinetic study of asiatic acid tromethamine salt-loaded solid lipid nanoparticles. Drug Dev. Ind. Pharm. 2016, 42, 1325-1333. [CrossRef] [PubMed]

43. Das, S.; Chaudhury, A. Recent advances in lipid nanoparticle formulations with solid matrix for oral drug delivery. AAPS PharmSciTech 2011, 12, 62-76. [CrossRef] [PubMed]

44. Gaumet, M.; Vargas, A.; Gurny, R.; Delie, F. Nanoparticles for drug delivery: The need for precision in reporting particle size parameters. Eur. J. Pharm. Biopharm. 2008, 69, 1-9. [CrossRef]

45. Gupta, M.; Vyas, S.P. Development, characterization and in vivo assessment of effective lipidic nanoparticles for dermal delivery of fluconazole against cutaneous candidiasis. Chem. Phys. Lipids 2012, 165, 454-461. [CrossRef]

46. You, J.; Wan, F.; de Cui, F.; Sun, Y.; Du, Y.-Z.; qiang Hu, F. Preparation and characteristic of vinorelbine bitartrate-loaded solid lipid nanoparticles. Int. J. Pharm. 2007, 343, 270-276. [CrossRef]

47. Hu, F.-Q.; Jiang, S.-P.; Du, Y.-Z.; Yuan, H.; Ye, Y.-Q.; Zeng, S. Preparation and characterization of stearic acid nanostructured lipid carriers by solvent diffusion method in an aqueous system. Colloids Surf. B Biointerfaces 2005, 45, 167-173. [CrossRef]

48. Zhang, J.; Zhu, X.; Jin, Y.; Shan, W.; Huang, Y. Mechanism study of cellular uptake and tight junction opening mediated by goblet cell-specific trimethyl chitosan nanoparticles. Mol. Pharm. 2014, 11, 1520-1532. [CrossRef]

49. Chai, G.-H.; Hu, F.-Q.; Sun, J.; Du, Y.-Z.; You, J.; Yuan, H. Transport pathways of solid lipid nanoparticles across Madin-Darby canine kidney epithelial cell monolayer. Mol. Pharm. 2014, 11, 3716-3726. [CrossRef]

50. Wang, D.; Zhao, P.; Cui, F.; Li, X. Preparation and characterization of solid lipid nanoparticles loaded with total flavones of Hippophae rhamnoides (TFH). PDA J. Pharm. Sci. Technol. 2007, 61, 110-120.

51. Freitas, C.; Müller, R.H. Effect of light and temperature on zeta potential and physical stability in solid lipid nanoparticle (SLN ${ }^{\mathrm{TM}}$ ) dispersions. Int. J. Pharm. 1998, 168, 221-229. [CrossRef]

52. Alexander, A.; Khichariya, A.; Gupta, S.; Patel, R.J.; Giri, T.K.; Tripathi, D.K. Recent expansions in an emergent novel drug delivery technology: Emulgel. J. Control. Release 2013, 171, 122-132.

53. Aburahma, M.H.; Badr-Eldin, S.M. Compritol 888 ATO: A multifunctional lipid excipient in drug delivery systems and nanopharmaceuticals. Expert Opin. Drug Deliv. 2014, 11, 1865-1883. [CrossRef] [PubMed]

54. Doijad, R.; Manvi, F.; Godhwani, D.; Joseph, R.; Deshmukh, N. Formulation and targeting efficiency of cisplatin engineered solid lipid nanoparticles. Indian J. Pharm. Sci. 2008, 70, 203. [CrossRef]

55. Das, S.; Ng, W.K.; Tan, R.B. Are nanostructured lipid carriers (NLCs) better than solid lipid nanoparticles (SLNs): Development, characterizations and comparative evaluations of clotrimazole-loaded SLNs and NLCs? Eur. J. Pharm. Sci. 2012, 47, 139-151. [CrossRef]

56. zur Mühlen, A.; Schwarz, C.; Mehnert, W. Solid lipid nanoparticles (SLN) for controlled drug delivery-drug release and release mechanism. Eur. J. Pharm. Biopharm. 1998, 45, 149-155. [CrossRef] 
57. Gordillo-Galeano, A.; Mora-Huertas, C.E. Solid lipid nanoparticles and nanostructured lipid carriers: A review emphasizing on particle structure and drug release. Eur. J. Pharm. Biopharm. 2018, 133, 285-308. [CrossRef]

58. Wang, R.-B.; Lv, H.-N.; Zhu, S.-S.; Ren, X.-D.; Xu, S.; Ma, S.-G.; Liu, Y.-B.; Qu, J.; Yu, S.-S. A novel and practical synthesis of CAT3: A phenanthroindolizidine alkaloid with potential in treating glioblastoma. RSC Adv. 2018, 8, 29301-29308. [CrossRef]

(C) 2020 by the authors. Licensee MDPI, Basel, Switzerland. This article is an open access article distributed under the terms and conditions of the Creative Commons Attribution (CC BY) license (http://creativecommons.org/licenses/by/4.0/). 